\title{
Characterization of the rainbow trout spleen transcriptome and identification of immune-related genes
}

\author{
Ali Ali ${ }^{1,2}$, Caird E. Rexroad ${ }^{3}$, Gary H. Thorgaard ${ }^{4}$, Jianbo Yao ${ }^{5}$ and Mohamed Salem ${ }^{1,5 *}$ \\ Department of Biology, Middle Tennessee State University, Murfreesboro, TN, USA \\ ${ }^{2}$ Department of Zoology, Faculty of Science, Benha University, Benha, Egypt \\ ${ }^{3}$ The National Center for Cool and Cold Water Aquaculture, United States Department of Agriculture Agricultural Research Service, Leetown, WV USA \\ ${ }^{4}$ School of Biological Sciences, Washington State University, Pullman, WA, USA \\ ${ }^{5}$ Division of Animal and Nutritional Science, West Virginia University, Morgantown, WV, USA
}

\section{Edited by:}

José Manuel Yáñez, University of

Chile, Chile

\section{Reviewed by:}

Alexandre Rodrigues Caetano, Embrapa Recursos Genéticos e Bioteclogia, Brazil

Ed Smith, Virginia Polytechnic

Institute and State University, USA

\section{*Correspondence:}

Mohamed Salem, Department of

Biology, Box 60, 2055 SCl, 1500

Greenland Dr., Murfreesboro,

TN 37132, USA

e-mail: mohamed.salem@mtsu.edu
Resistance against diseases affects profitability of rainbow trout. Limited information is available about functions and mechanisms of teleost immune pathways. Immunogenomics provides powerful tools to determine disease resistance genes/gene pathways and develop genetic markers for genomic selection. RNA-Seq sequencing of the rainbow trout spleen yielded 93,532,200 reads (100 bp). High quality reads were assembled into 43,047 contigs. $26,333(61.17 \%)$ of the contigs had hits to the NR protein database and $7024(16.32 \%)$ had hits to the KEGG database. Gene ontology showed significant percentages of transcripts assigned to binding $(51 \%)$, signaling (7\%), response to stimuli $(9 \%)$ and receptor activity $(4 \%)$ suggesting existence of many immune-related genes. KEGG annotation revealed 2825 sequences belonging to "organismal systems" with the highest number of sequences, $842(29.81 \%)$, assigned to immune system. A number of sequences were identified for the first time in rainbow trout belonging to Toll-like receptor signaling (35), B cell receptor signaling pathway (44), T cell receptor signaling pathway (56), chemokine signaling pathway (73), Fc gamma R-mediated phagocytosis (52), leukocyte transendothelial migration (60) and NK cell mediated cytotoxicity (42). In addition, 51 transcripts were identified as spleen-specific genes. The list includes 277 full-length cDNAs. The presence of a large number of immune-related genes and pathways similar to other vertebrates suggests that innate and adaptive immunity in fish are conserved. This study provides deep-sequence data of rainbow trout spleen transcriptome and identifies many new immune-related genes and full-length cDNAs. This data will help identify allelic variations suitable for genomic selection and genetic manipulation in aquaculture.

Keywords: spleen transcriptome, annotation, KEGG, immune-related genes, spleen-specific genes, full-length cDNA

\section{INTRODUCTION}

Teleost fish are the first class of vertebrates that have the elements of both innate and adaptive immune responses (Whyte, 2007). Innate immunity is more important in teleosts as the first line of defense due to the restrictions on adaptive immunity in suboptimal environments (Ullal et al., 2008). Teleost fish have no bone marrow or lymph nodes. Immunogenomics can be used in clarifying the origin and evolution of the immune systems (Kaiser et al., 2008).

The ability of fish to combat viral, bacterial or parasitic pathogen is affected by genetic factors. Thus, genetic selection can improve disease resistance and provide prolonged protection against pathogens (Skamene and Pietrangeli, 1991; Wiegertjes et al., 1996; Van Muiswinkel et al., 1999; Leeds et al., 2010; Wiens et al., 2013a). In addition, investigations on immune reactions in fish could aid in development of vaccines (Raida and Buchmann, 2009).
Rainbow trout (Oncorhynchus mykiss) are widely distributed and cultured aquaculture species used as a food and sport fish (Thorgaard et al., 2002). Additionally, this organism is used as a model species in many different fields of research such as cancer biology (Tilton et al., 2005), toxicology (Köllner et al., 2002), nutrition (Wong et al., 2013), evolutionary biology (Taylor et al., 2011), and immunology (Nya and Austin, 2011). Rainbow trout are larger than other fish model species, making them a source of large quantities of specific tissues and cells for immunological, biochemical and molecular analyses. Several genomic resources have been developed for research to help improve rainbow trout commercial production traits including disease resistance. The list includes clonal lines (Young et al., 1996; Thorgaard et al., 2002), BAC libraries (Palti et al., 2004), genetic linkage maps (Young et al., 1998; Sakamoto et al., 2000; Rexroad et al., 2008; Palti et al., 2011; Guyomard et al., 2012), microarrays (Salem et al., 2008), expressed sequence tags (ESTs) (Rexroad et al., 2003; 
Sánchez et al., 2009; Boussaha et al., 2012), single nucleotide polymorphisms (SNPs) (Sánchez et al., 2009; Amish et al., 2012; Boussaha et al., 2012; Houston et al., 2012; Salem et al., 2012; Christensen et al., 2013; Colussi et al., 2014; Palti et al., 2014), next-generation sequence read archives (SRA) and genome as well as transcriptome reference assemblies (Salem et al., 2010; Sanchez et al., 2011; Berthelot et al., 2014; Fox et al., 2014). Several studies have identified many immune-related key genes and gene networks (Thorgaard et al., 2002; Cerdà et al., 2008; Chiu et al., 2010; Zhang et al., 2011). Immunogenomic studies of rainbow trout have established an agricultural importance due to their direct and immediate contributions to the aquaculture industry (Thorgaard et al., 2002).

The spleen is a primary hematopoietic and peripheral lymphoid organ (Zapata et al., 2006; Mahabady et al., 2012). This organ has melano-macrophage centers for breakdown of aged erythrocytes, and T-like as well as B-like cells for antigen trapping. In addition, spleen has a role in antigen presentation and initiation of the adaptive immune response (Espenes et al., 1995; Zapata et al., 1997; Chaves-Pozo et al., 2005; Whyte, 2007; Alvarez-Pellitero, 2008). Positive genetic correlation exists between bacterial cold water disease resistance and spleen index in domesticated rainbow trout (Wiens et al., 2013b).

Transcriptomic profiling is useful in revealing spleen genes that are engaged in the innate and adaptive immune responses and expressed as a result of the presence of toxicants or infection (Pereiro et al., 2012). RNA-Seq (whole transcriptome sequencing) is an effective tool for identifying the functional complexity of transcriptomes, alternative splicing, non-coding RNAs, new transcription units and assembly of full-length genes (Xiang et al., 2010; Huang et al., 2011; Salem et al., 2012; Djari et al., 2013). This deep sequencing technology gives low background noise, aids in identifying allele-specific expression and reveals weakly expressed transcripts. Bioinformatics algorithms were developed facilitating transcriptomic profiling (Yang et al., 2012). Therefore, RNA-Seq is a valuable tool in studying functional complexity of the spleen transcriptome and identifying immune-relevant genes and signaling networks (Nie et al., 2012).

In this study, we aimed to (1) characterize the transcriptome of rainbow trout spleen and (2) identify spleen-specific and immune-relevant genes (including full-length cDNAs) that could be used to develop genetic markers for disease resistance. Identifying the networks associated with such genes will be helpful in generating new technologies to improve aquaculture (Takano et al., 2011).

\section{RESULTS AND DISCUSSION}

The spleen transcriptome was sequenced from an apparently healthy single homozygous doubled-haploid fish from the Swanson clonal line, the same line used for BAC library construction (Palti et al., 2004) and sequencing both of the whole transcriptome (Salem et al., 2010) and the whole genome reference (Berthelot et al., 2014). A single doubled-haploid fish was used to help overcome the assembly complications associated with the tetraploid genome of the rainbow trout (Allendorf and Thorgaard, 1984). Spleen transcriptome RNA-Seq data were de novo assembled into contigs. Assembled contigs were analyzed and annotated to identify genes that are predominantly expressed in the spleen and genes that are involved in immune signaling pathways. Spleen sequencing data yielded a total of 93,532,200 reads with a read length of at least $100 \mathrm{bp}$. After filtration to remove the adaptors, low complexity reads and duplicates, 58,013,135 (62\%) high quality reads ( $Q$ values $>33 \%$ ) were obtained and assembled into 43,047 contigs with an average contig length of $1154 \mathrm{nt}$ and N50 equal to $1306 \mathrm{nt}$.

\section{FUNCTIONAL ANNOTATION}

Contigs were searched against the NCBI's non-redundant protein (NR) database using the BLASTX program with $E$-value of $1.0 \mathrm{E}-3$. There were $26,333(61.17 \%)$ contigs with hits to the NR database (Table S1). The contigs which had no hits $[16,714$ $(38.83 \%)]$ may be attributed to non-coding RNAs, contig misassembles (Grabherr et al., 2011), limited information about protein sequences of related fish in the NCBI database or diverged sequences of rainbow trout due to partial genome duplication (Ravi and Venkatesh, 2008; Lee et al., 2011). Further work toward characterization of the non-coding RNAs is still needed.

Data statistics of the sequencing, assembly and annotations are presented in Table 1. A total of 13,780 (88.40\%) of the contigs of more than $1000 \mathrm{bp}$ in length had BLAST matches, whereas only 12,543 (51.72\%) of contigs shorter than $1000 \mathrm{bp}$ had BLAST hits (Figure 1). Short sequences may give false-negative results because they are not long enough to show sequence matches or may lack a representative protein domain (Wang et al., 2012). The identity distribution revealed that $70 \%$ of the contigs have greater than $80 \%$ similarity and $24 \%$ possess identity similarities between 60 and $80 \%$. The $E$-value distribution of the top

Table 1 | Statistical summary of rainbow trout spleen sequencing, assembly and annotation.

Data generation and filtration

Total number of reads

$93,532,200$

Total number of duplicates

$35,519,065(38 \%)$

Number of high quality reads

$58,013,135(62 \%)$

\section{Assembly statistics}

Number of bases

$49,669,063$

Number of long contigs $(\geq 500)$

43,047

Largest contig length (nt)

14,276

Smallest contig length (nt)

500

Average contig length (nt)

1154

$\mathrm{N} 50$ (nt)

1306

\section{Annotation}

Total number of annotated contigs

43,047

Number of contigs with NR hits

$26,333(61.17 \%)$

Number of contigs without NR hits

$16,714(38.83 \%)$

Number of contigs with KEGG hits

$7024(16.32 \%)$

Number of contigs without KEGG hits 


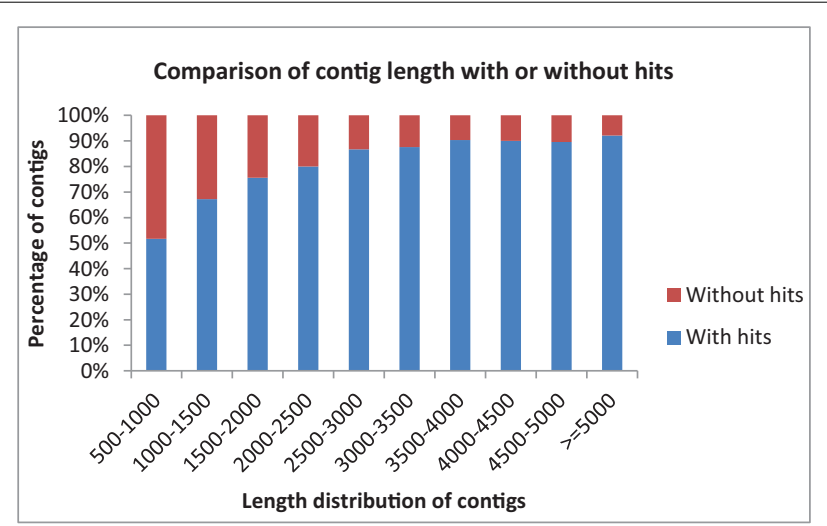

FIGURE 1 | Comparison of contig length with and without BLASTX hits to the NR database.

hits to the NR database showed that $28 \%$ of the assembled contigs showed significant homology to previously deposited sequences (less than 1.0E-50), and $72 \%$ ranged from $1.0 \mathrm{E}-50$ to 0 . The assembled contigs have been submitted to the NAGRP Aquaculture Genome Projects (http://www.animalgenome.org/ repository/pub/MTSU2014.0811/).

Gene ontology (GO) categorizes gene products and standardizes their representation across species (Consortium, 2008). Contigs with lengths of 500 nucleotides or more $(43,047)$ were annotated using the Blast2GO suite (Conesa et al., 2005; Götz et al., 2008); contigs were assigned to appropriate molecular function, biological process and cellular component GO terms (Ashburner et al., 2000). Figure 2 shows summary of the GO assignments at the second level in the three areas of gene ontology. GO term distribution was compared to a transcriptome reference that we previously assembled from 13 tissues (Salem et al., 2010) (Figure 3). In the biological process category, the most represented terms were related to cellular process $(17 \%)$, followed by metabolic process $(15 \%)$ and biological regulation (12\%) (Figure 2A). These percentages are lower than the corresponding categories at the whole transcriptome reference; 25, 18, and $25 \%$, respectively (Figure $3 \mathbf{A}$ ). Conversely, some immunerelevant sub-categories of metabolic processes exist in higher percentages compared to counterparts at sub-categories at the whole transcriptome reference; response to stimuli (9\%) and signaling (7\%) compared to $3 \%$ response to stimuli and $1 \%$ immune system process, respectively (Figure 3A). These percentages suggest that we identified a larger number of immune-related genes in this study.

Within the molecular function category, 51, 30, and $4 \%$ of the spleen transcripts were assigned to binding, catalytic activity and receptor activity, respectively. The whole transcriptome reference showed 46 and $32 \%$ and unlisted percentage, respectively (Figure 3B). Pereiro and co-workers suggested several immune-related processes were represented in the binding and catalytic activity categories (Pereiro et al., 2012). In the cellular component categories, a significant percentage of clusters assigned to cell $(42 \%)$, organelle $(27 \%)$, macromolecular complex $(13 \%)$, membrane enclosed lumen $(8 \%)$ and membrane
7\% (Figure 3C) compared to their corresponding categories at the whole transcriptome reference; 59, 24, 9, 3\% and unlisted percentage, respectively (Figure 3C). Discrepancies in the GO distribution profiles may be attributed to differences in the nature of the cDNA libraries, the numbers of sequences used to retrieve GO terms, sequencing technology and the assembly approaches. Information about GO terms is supplied in additional Table S2.

KEGG pathway analysis was carried out to categorize and annotate the assembled contigs (Kanehisa and Goto, 2000; Kanehisa et al., 2012). Searching contigs against the KEGG database yielded 7,024 KEGG hits $(16.32 \%$ of the total number of transcripts), with 4779 unique hits $(11.10 \%$ of total number of transcripts). KEGG Orthology (KO) numbers were used to assign sequences to different metabolic pathways (Table 2). In total, 2236 (31.83\% of the total number of KEGG hits) KEGG annotated sequences were assigned to metabolism that was further classified into carbohydrate metabolism (453 sequences, $20.26 \%$ ), lipid metabolism (349 sequences, $15.61 \%$ ) and amino acid metabolism (343 sequences, 15.34\%). In addition, 1,394 $(19.85 \%)$ annotated sequences were assigned to genetic information processing which includes folding, sorting and degradation (484 sequences, 34.72\%), translation (459 sequences, $32.93 \%)$, replication and repair (255 sequences, $18.29 \%$ ), and transcription (196 sequences, 14.06\%). Further, 1830 sequences (26.05\%) were classified as environmental information processing assigning 1508 sequences $(82.40 \%)$ to signal transduction and 283 sequences $(15.46 \%)$ to signaling molecules and interaction. The Cellular processes group contained 1421 (20.23\%) KEGG-annotated sequences.

Remarkably, the KEGG organismal systems category contained $2825(40.22 \%)$ annotated sequences with the highest number of sequences assigned to immune system (842 sequences, 29.81\%) followed by endocrine system (619 sequences, $21.91 \%$ ), nervous system (526 sequences, $18.62 \%$ ), digestive system (268 sequences, 9.49\%) and development (210 sequences, 7.43\%). Assignments of the organismal systems to the last four categories support the previously reported relationships between function of the spleen and other systems of the body. For example, a subset of genes with functions relevant to neurodevelopment was identified in the spleen transcriptome of the house finch (Haemorhous mexicanus) (Backström et al., 2013). Regarding the endocrine functions, it was thought that spleen secretes a hormone-like substance under the control of pituitary gland and adrenal cortex in case of emergencies (Ungar, 1945). Recently, the spleen endocrine function has been confirmed after in-depth studies of its function (Wu, 1998; Horiguchi et al., 2004; Tarantino et al., 2011). A cytokine known as Lymphotoxin was reported to keep the immunological balance of the gastrointestinal tract through regulation of the immune system of the digestive tract which is represented by immune cells, immunoglobulins and intestinal bacteria (Kruglov et al., 2013). In addition, hormones of the gastrointestinal tract activate the immune system in case of gut inflammation (Khan and Ghia, 2010).

\section{TAXONOMIC ANALYSIS}

A BLASTX top-hit species distribution of gene annotations showed highest homology to Salmo salar (4,833 BLAST hits; 

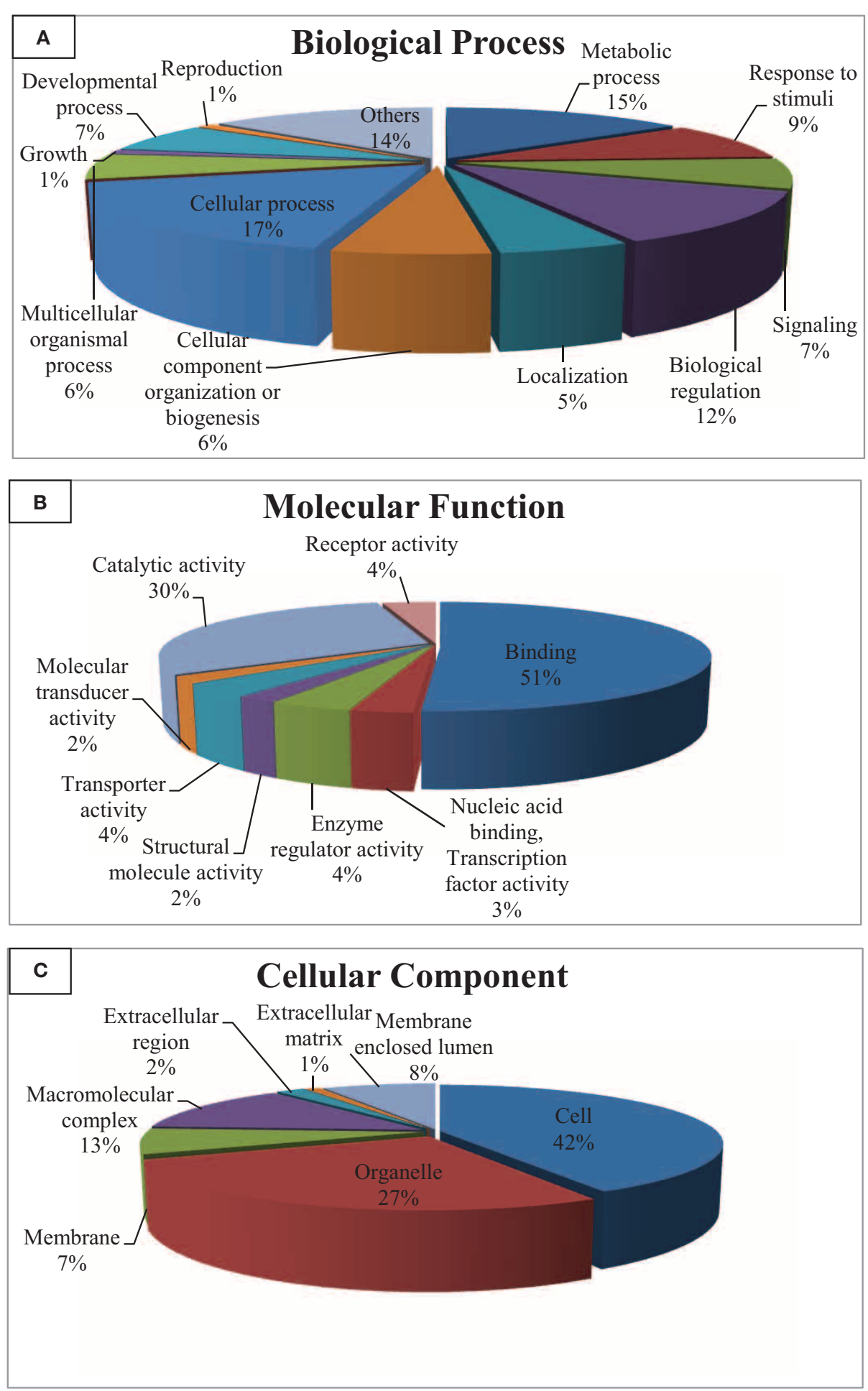

FIGURE 2 | Gene ontology (GO) assignments (2nd level GO terms) for the spleen transcriptomic sequences of rainbow trout. (A) Refers to biological process, (B) refers to molecular function and (C) refers to cellular component.

18.35\%), followed by Oreochromis niloticus (16.64\%), Maylandia zebra $(16.47 \%)$ and Danio rerio (16.12\%) (Figure 4). Other fish species in the BLASTX top-hit were Takifugu rubripes (5.98\%) and Oryzias latipes (5.17\%). Rainbow trout itself (983 BLAST hits;
$3.73 \%$ ) fell in the seventh position of the top-hit species distribution. This may be explained by identification of a large number of new genes in this study and/or and existence of a limited number of rainbow trout proteins (6965 proteins) that currently available 


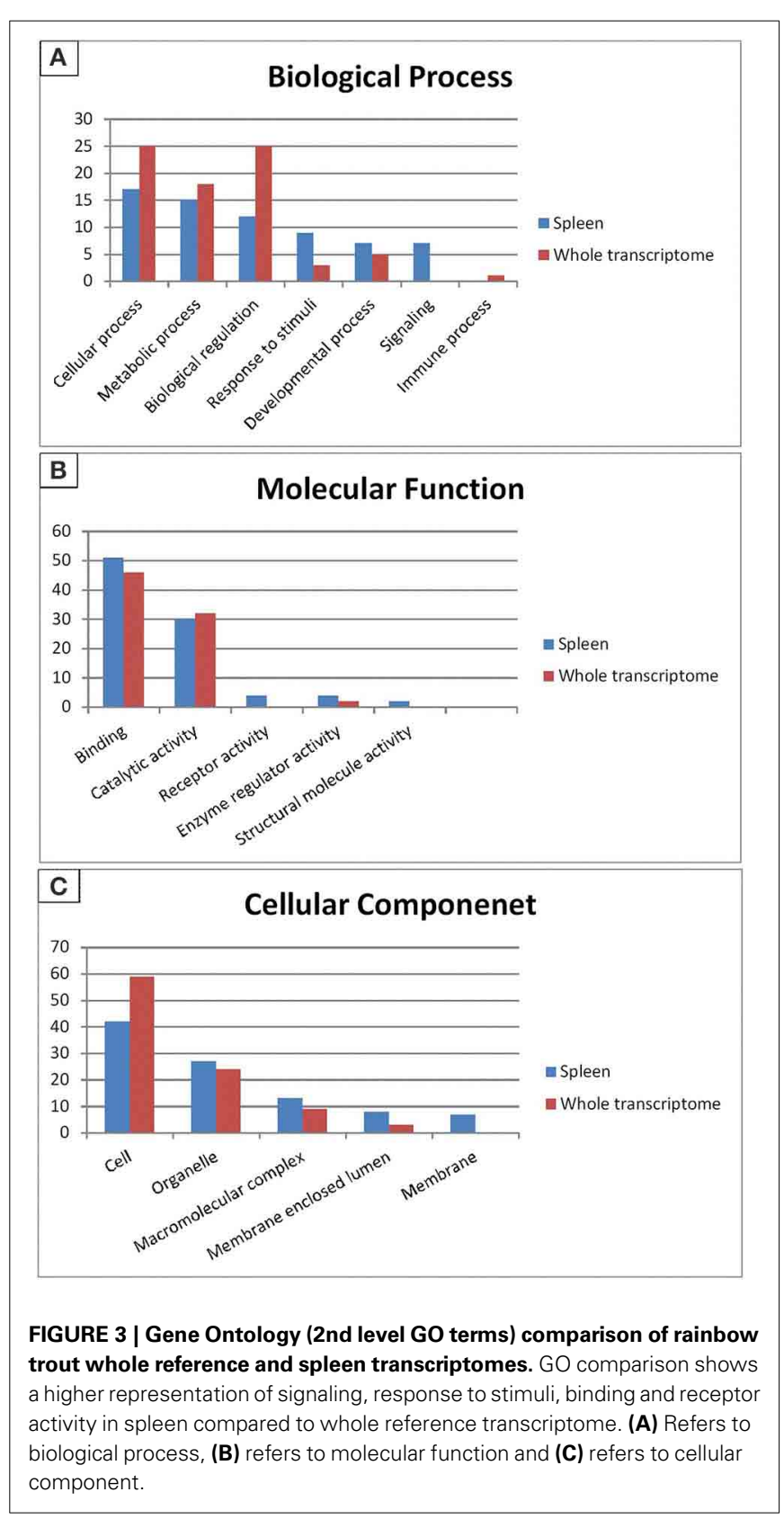

at NCBI database. The model fish species in the list, D. rerio, T. rubripes and $O$. latipes, have large number of proteins available in the NCBI database. All first nine species were fish, starting with $S$. salar from the family Salmonidae to which rainbow trout belongs. Therefore, these results support the high quality and high level of phylogenetic conservation of the assembled spleen transcriptome. Other species with known genome sequences appearing in the BLASTX top-hit species distribution were mammals including Homo sapiens, Mus musculus, and Rattus norvegicus, Gallus (chicken) and the amphibian Xenopus laevis.

\section{IMMUNE TRANSCRIPTOME ANALYSIS}

Our transcriptome analysis identified 842 immune-related transcripts in 15 KEGG immune pathways, (Table S3). Many of
Table 2 | KEGG biochemical mappings for rainbow trout.

\begin{tabular}{|c|c|c|}
\hline KEGG categories & $\begin{array}{c}\text { No. of annotated } \\
\text { sequences (\%) }\end{array}$ & $\begin{array}{l}\text { Number of } \\
\text { KOs }\end{array}$ \\
\hline Metabolism & 2236 & 1496 \\
\hline Carbohydrate metabolism & $453(20.26)$ & 281 \\
\hline Lipid metabolism & $349(15.61)$ & 220 \\
\hline Amino acid metabolism & $343(15.34)$ & 239 \\
\hline Glycan biosynthesis and metabolism & $273(12.21)$ & 187 \\
\hline Nucleotide metabolism & $220(9.84)$ & 152 \\
\hline Energy metabolism & $189(8.45)$ & 132 \\
\hline Metabolism of cofactors and vitamins & $129(5.77)$ & 99 \\
\hline Metabolism of other amino acids & $105(4.70)$ & 63 \\
\hline Xenobiotic biodegradation and metabolism & $99(4.43)$ & 69 \\
\hline Biosynthesis of secondary metabolites & $38(1.70)$ & 25 \\
\hline Metabolism of teroenoids and polyketides & $38(1.70)$ & 29 \\
\hline Genetic information processing & 1394 & 920 \\
\hline Folding, sorting and degradation & $484(34.72)$ & 311 \\
\hline Translation & 459 (32.93) & 283 \\
\hline Replication and repair & $255(18.29)$ & 196 \\
\hline Transcription & $196(14.06)$ & 130 \\
\hline Environmental information processing & 1830 & 1169 \\
\hline Signal transduction & $1508(82.40)$ & 909 \\
\hline Signaling molecules and interaction & $283(15.46)$ & 227 \\
\hline Membrane transport & $39(2.13)$ & 33 \\
\hline Cellular processes & 1421 & 905 \\
\hline Cell growth and death & $485(34.13)$ & 306 \\
\hline Transport and catabolism & $434(30.54)$ & 295 \\
\hline Cell communication & $358(25.19)$ & 215 \\
\hline Cell motility & $144(10.13)$ & 89 \\
\hline Organismal systems & 2825 & 1777 \\
\hline Immune system & $842(29.81)$ & 541 \\
\hline Endocrine system & $619(21.91)$ & 378 \\
\hline Nervous system & $526(18.62)$ & 334 \\
\hline Digestive system & $268(9.49)$ & 166 \\
\hline Development & $210(7.43)$ & 132 \\
\hline Excretory system & $126(4.46)$ & 73 \\
\hline Circulatory system & $103(3.65)$ & 69 \\
\hline Environmental adaptation & $88(3.12)$ & 56 \\
\hline Sensory system & $43(1.52)$ & 28 \\
\hline Total & 9706 & 6267 \\
\hline
\end{tabular}

these transcripts are represented by complete cDNA sequences that were identified for the first time in rainbow trout. The immune-related transcripts were mapped to a newly assembled genome reference (Berthelot et al., 2014). The coordinate genome reference IDs and complete/incomplete ORF conditions are provided in Tables S4-S10. The immune-related transcripts were clustered according to their KEGG assigned pathways (Figure 5).

\section{Toll-like receptor signaling pathway}

Toll-like receptors (TLRs) activate the innate immune response through recognition of pathogen associated molecular patterns (PAMPs) including lipopolysaccharides or peptidoglycan in bacterial cell wall, $\beta$-1,3-glucan on fungal cell wall and dsRNA from viruses (Medzhitov and Janeway, 2000; Janeway and Medzhitov, 2002). This leads to the activation of nuclear factor- kB (NF-kB) 


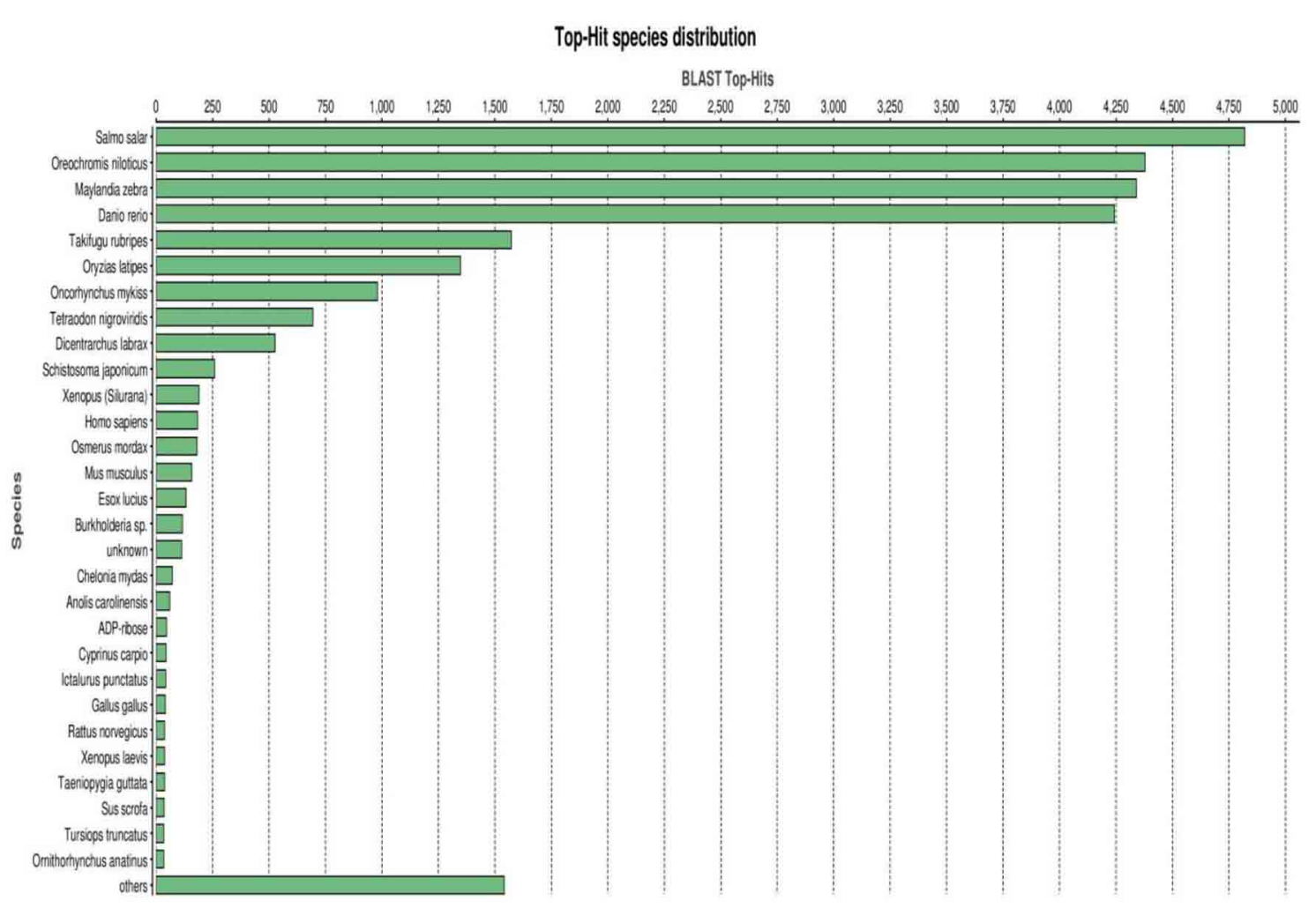

FIGURE 4 | BLASTX top-hit species distribution of gene annotations showing high homology to fish species with known genome sequences.

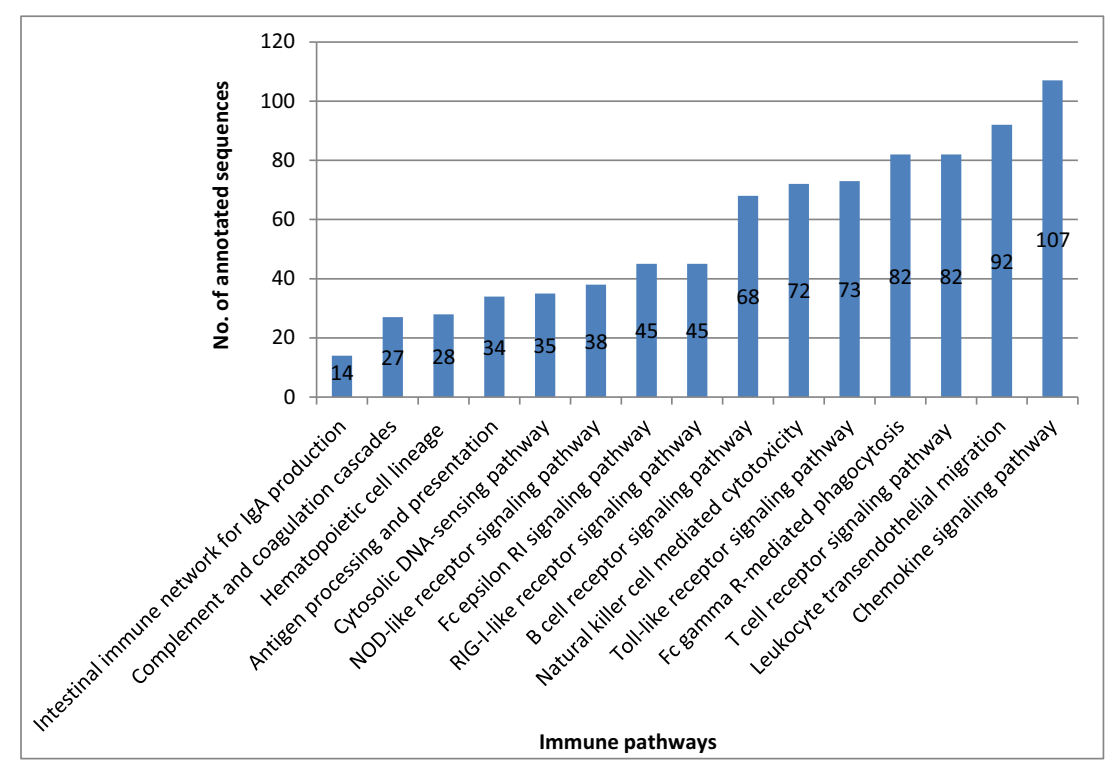

FIGURE 5 | Number of all annotated sequences obtained from the different KEGG immune pathway mapping.

that in turn induces proinflammatory cytokines (Barton and Medzhitov, 2003; Takeda and Akira, 2004).

More than 10 TLRs have been identified in teleost fish including zebrafish (Jault et al., 2004; Meijer et al., 2004), rainbow trout (Tsujita et al., 2004; Palti et al., 2010a), common carp (Kongchum et al., 2010), pufferfish (Oshiumi et al., 2003), channel catfish (Bilodeau and Waldbieser, 2005; Baoprasertkul et al., 2007a,b) and Atlantic salmon (Rebl et al., 2007). In our spleen 
transcriptomic data, there were 7 transcripts, as represented in Table S4, showing high similarity to TLR1, TLR2, TLR3, TLR5, TLR7/8, and TLR9. The coordinate genome reference IDs were identified and five transcripts matching TLR1, TLR3, TLR7, TLR8, and TLR9 had complete cDNA sequences. Several TLRs were previously identified in rainbow trout (Tsujita et al., 2004; Rodriguez et al., 2005; Ortega-Villaizan et al., 2009; Palti et al., 2010a,b). TLR4 was not reported in teleosts except zebrafish whereas TLR6 is totally missing in teleost fish (Takano et al., 2011). This study supports the notion of absence of both TLR4 and TLR6 in rainbow trout.

There were three transcripts matching the NF-кB complex. Two transcripts matched each of MKK4/7 and IFN- $\alpha \beta R$ complexes. Each of MKK3/6 and MEK1/2 complexes has one transcript whereas MAP2K3 and MAP2K1 have no matches. Additionally, AP-1 which is composed of JUN and FOS (Zenz et al., 2008) had only one transcript matching JUN. The remaining 56 transcripts, out of the 73 total transcripts, showed high similarity to other members of the TLR signaling pathway of higher vertebrates (Figure 6). A total of 38 transcripts have complete cDNA sequences. To our knowledge, 26 different proteins were annotated for the first time in rainbow trout in the current study. Information about transcripts that showed homology to molecules involved in Toll-like receptor signaling pathway is included in additional Table S4.

\section{B cell receptor signaling pathway}

B-lymphocytes are involved in antigen specific defense. They are activated through binding of antigen to B cell receptors. These cells produce specific antibodies to neutralize the foreign particles
(Kurosaki et al., 2010). The binding of antigen to B-cell receptor activates B lymphocytes (Batista and Neuberger, 1998). Figure 7 shows all B cell signaling pathway annotated and non-annotated proteins in the current study. A total of 68 sequences were assigned to the B cell signaling pathway, 44 have been identified for the first time in this transcriptomic study. Information about transcripts that showed homology to molecules involved in B cell receptor signaling pathway is included in additional Table S5.

\section{T cell receptor signaling pathway}

Like B cells, T lymphocytes are involved in the antigen specific defense. Both T cell receptors (TCR) and costimulatory molecules such as CD28 are required for T cell activation. The cytotoxicity of Cytotoxic T lymphocytes in fish is obscure due to lack of suitable experimental systems even though few studies have depicted the lysis of virus-infected cells by NK-like cells in rainbow trout (Moody et al., 1985; Yoshinaga et al., 1994) and channel catfish (Hogan et al., 1996). Information about proteins that are involved in this cascade was very limited in rainbow trout. The annotated transcripts showed high similarity to many members of the $\mathrm{T}$ cell receptor signaling pathway of higher vertebrates as shown in Figure 8. In this study, many transcripts (56 out of 82 ) that are included in $\mathrm{T}$ cell receptor signaling pathway were identified for the first time. Information about transcripts that showed homology to molecules involved in $\mathrm{T}$ cell receptor signaling pathway is included in additional Table S6.

\section{Chemokine Signaling Pathway}

Chemokines have a major role in trafficking and activation of leukocytes toward the site of inflammation by the aid of

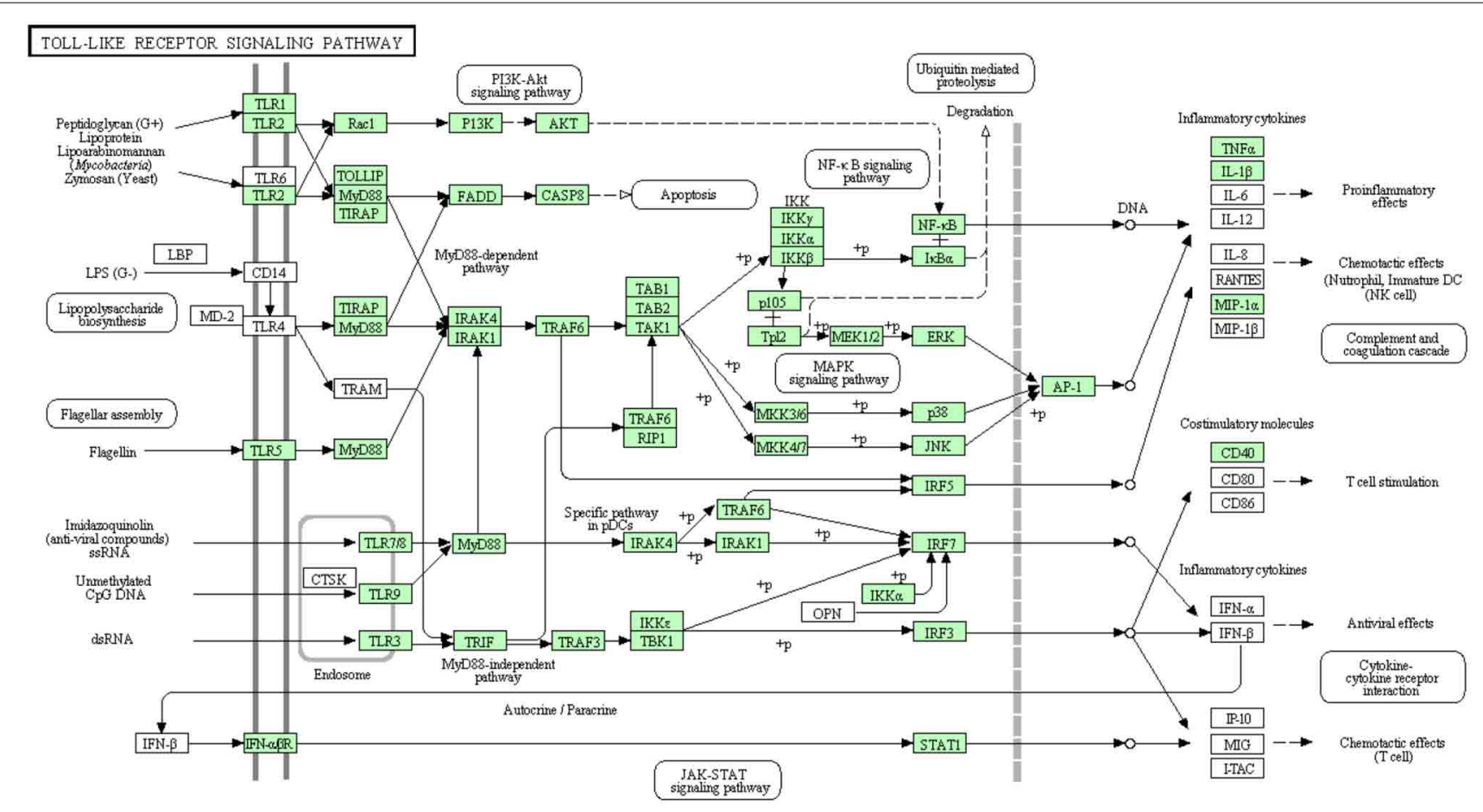

FIGURE 6 | Toll-like receptor signaling pathway showing the annotated and non-annotated proteins. Proteins appearing in our transcriptome are represented in green color and absent proteins in white color. 


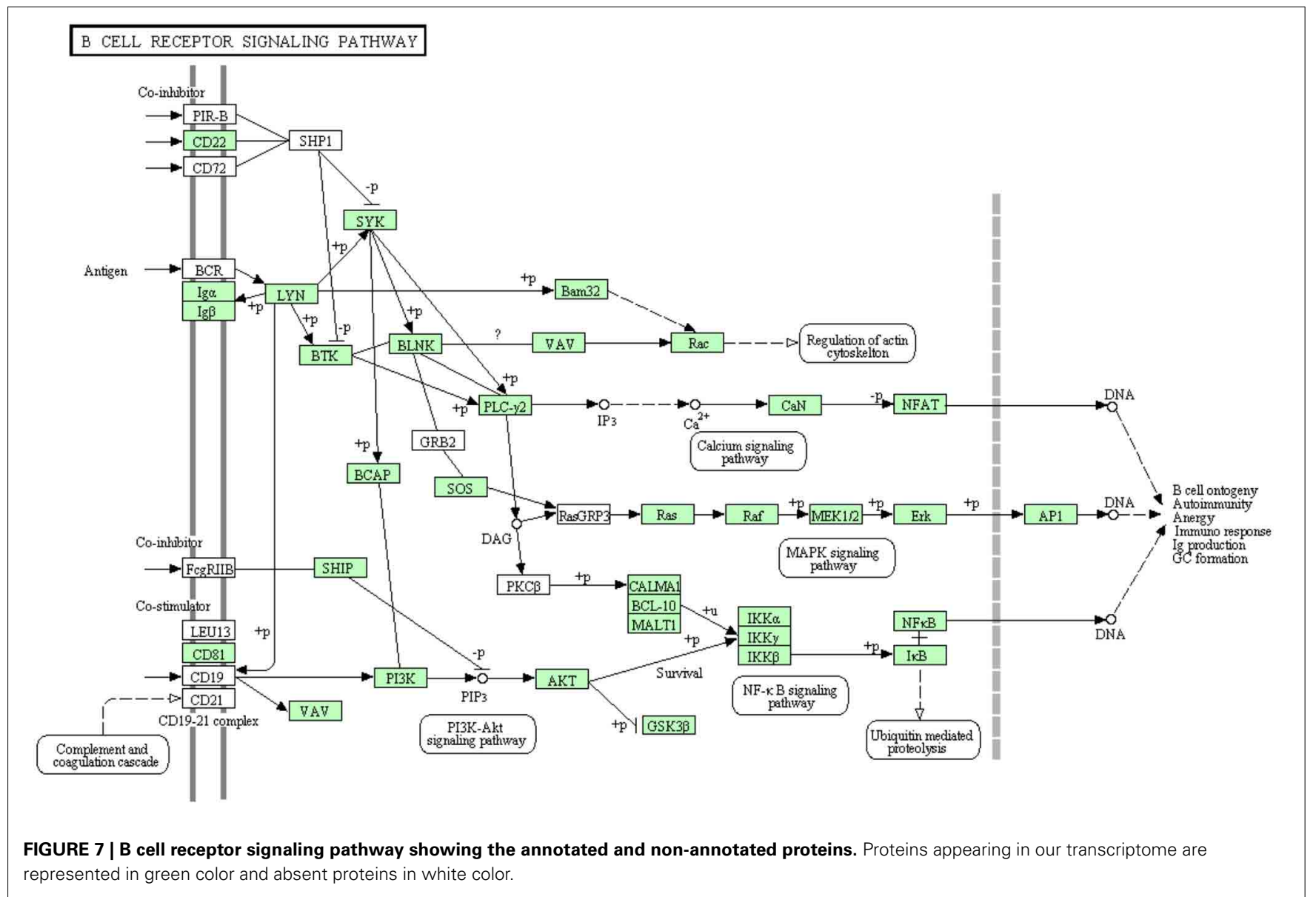

C-terminal domain of their receptors (chemotaxis) (Pease and Williams, 2006). Few chemokine-related genes have been cloned in rainbow trout including CCR9 (Dixon et al., 2013), CXCR4, CCR7 (Daniels et al., 1999) and CXCL14 (Bobe et al., 2006). Many of chemokine receptors haven't been reported to date in rainbow trout (Dixon et al., 2013). In the present study, most of the proteins in the chemokine signaling pathway have been identified (Figure 9). Out of 107 annotated transcripts, 73 sequences matching 49 proteins have been identified for the first time in rainbow trout. Information about transcripts that showed homology to molecules involved in chemokine signaling pathway was included in additional Table S7.

\section{Fc gamma R-mediated phagocytosis}

Clusters of IgG coat the foreign particles in a process termed opsonization. Leukocytes and tissue macrophages phagocytose the opsonized pathogens through Fc gamma receptors (Pacheco et al., 2013). Before the present study, some proteins were known to be involved in Fc gamma R-mediated phagocytosis as listed in Table S8. In the current transcriptome analysis, all annotated proteins belonging to the $\mathrm{Fc}$ gamma R-mediated phagocytosis are shown in Figure 10. There were 52 sequences out of 82 annotated sequences matching 30 proteins identified for the first time in rainbow trout. Information about transcripts that showed homology to molecules involved in the Fc gamma R-mediated phagocytosis signaling pathway is included in additional Table S8.

\section{Leukocyte transendothelial migration}

White blood cells migrate in an amoeboid fashion through the endothelium lining of the blood vessels to drive the immune response to the site of infection (Muller, 2011, 2013). Most of the proteins belonging to this pathway have been identified in this transcriptome analysis (Figure 11). There were 92 transcripts showing high similarity to members of the leukocyte transendothelial migration cascade of higher vertebrates. Prior to the current transcriptome sequencing, some proteins were previously annotated in rainbow trout (Table S9). To our knowledge, 36 proteins belonging to this pathway were reported for the first time in the current study. Information about transcripts that showed homology to molecules involved in leukocyte transendothelial migration is included in additional Table S9.

\section{Natural killer (NK) cell mediated cytotoxicity}

NK cells are lymphocytes working as a part of the innate immune system. Although they don't have classical antigen receptors like T and B lymphocytes, their receptors can discriminate between self and non-self-cells (Lanier, 2003). In the current transcriptome analysis, many but not all proteins that are involved in the NK cell mediated cytotoxicity pathway were annotated (Figure 12). Many proteins involved in this pathway were reported before the current study. In this cascade, 42 transcripts out of 72 identified sequences have been annotated for the first time in rainbow trout. The newly annotated transcripts matched 24 proteins. Information 


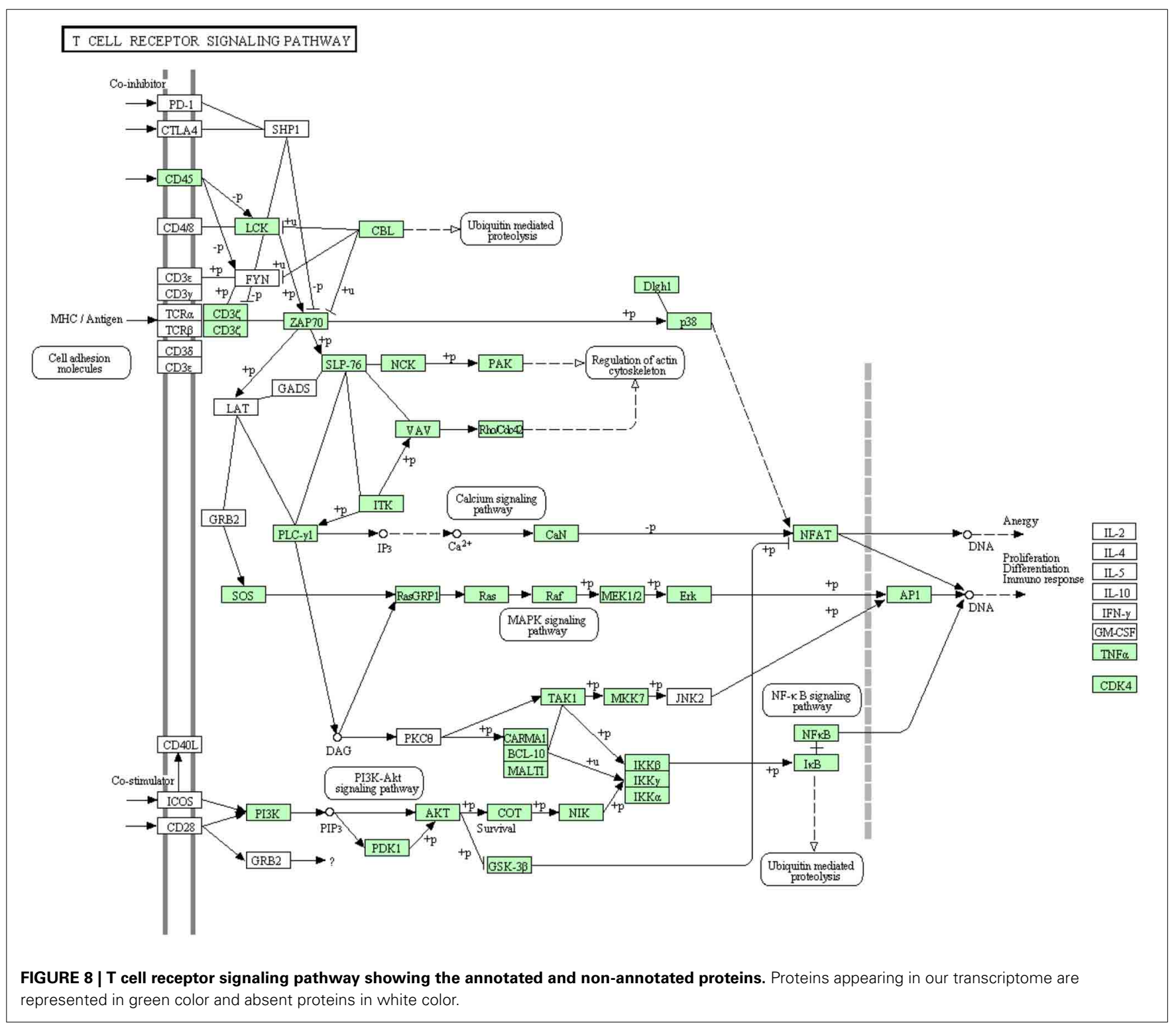

about transcripts that showed homology to molecules involved in NK cell mediated cytotoxicity signaling pathway is included in additional Table S10.

\section{SPLEEN-SPECIFIC GENES}

Recently, a total of 51 spleen-specific have been identified in our lab (data will be published elsewhere). The assembled contigs were submitted to the NAGRP Aquaculture Genome Projects (http://www.animalgenome.org/repository/pub/MTSU 2014.0811/). The coordinate IDs of the spleen-specific transcripts were determined using BLASTN (cut off $E$-value of 1.00E-10) against our spleen transcriptome (Table S11). As shown in Table S11, the level of gene expression was at least 20 fold higher in the spleen compared to 12 other tissues, with statistical false discovery rate (FDR) less than 5\%. The spleen-specific genes were mapped to the newly assembled genome reference (Berthelot et al., 2014). The coordinate genome reference IDs and complete/incomplete ORF conditions are provided in additional Table S11.
The list of spleen-specific genes includes: (1) Immune proteins include 5 transcripts such as Fc receptor-like protein 3like, thrombopoietin receptor precursor, P-selectin precursor, nuclear factor, interleukin 3 regulated (NFIL3), and lectin precursor. (2) Respiratory gas transport proteins include 4 most highly expressed transcripts assigned to hemoglobin and one transcript assigned to carbonic anhydrase II. A large representation of iron-binding proteins was reported in spleen of virus infected Turbot (Pereiro et al., 2012). (3) Coagulation cascade and adhesion proteins include 10 transcripts; five out of the ten transcripts were assigned to platelet glycoproteins whilst the other 5 transcripts were assigned to coagulation factor XIII A chain precursor, thrombopoietin receptor precursor, integrin alpha $2 \mathrm{~b}$, integrin beta-3-like and Von Willebrand factor. Thrombocytes appear in spleen during the first week postfertilization before appearing in blood because they participate in body defense (Tavares-Dias and Oliveira, 2009). (4) Development proteins involve 5 transcripts including ectodysplasin receptor, T-box 


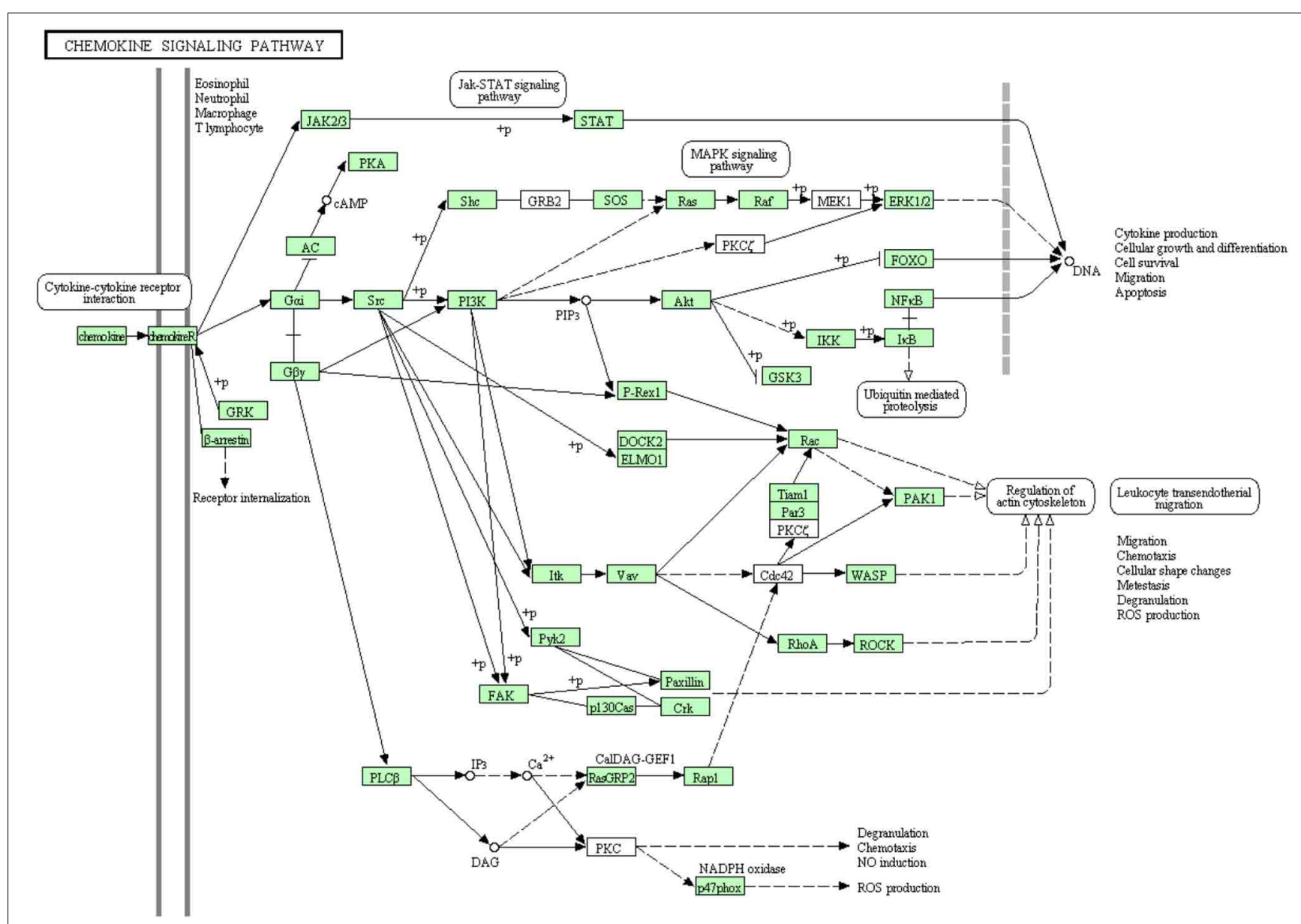

FIGURE 9 | Chemokine signaling pathway showing the annotated and non-annotated proteins. Proteins appearing in our transcriptome are represented in green color and absent proteins in white color.

transcription factor TBX6, homeobox proteins Nkx-2.6-like, Tcell leukemia homeobox protein 1 and Zinc finger protein Gfilb. The participation of the house finch (H. mexicanus) spleen transcriptome in neurodevelopment through a subset of genes has been already reported (Backström et al., 2013). (5) Transporter proteins include one transcript for band 3 anion exchange protein. Both of the biosynthetic and membrane incorporation processes of Band 3 protein have been studied in vivo in erythroid spleen cells (Sabban et al., 1981). Among the other identified spleen-specific genes was 5-aminolevulinate synthase erythroid specific mitochondrial precursor which is necessary for heme biosynthesis. Other spleen-specific genes such as rhomboid-like protease 4, Methionine aminopeptidase 2, zinc finger protein 143like, GATA binding factor 1, N-acetyltransferase 6-like, RING finger protein 151 and cytosolic purine $5^{\prime}$-nucleotidase were also expressed. In mouse and rat, 39 spleen-specific genes are found in tissue-specific database (Xiao et al., 2010). Moreover, 168 Refseq are preferentially expressed in human spleen based on ESTs (Liu et al., 2008). Further work is still needed to validate spleen-specific genes obtained from our high-throughput spleen transcriptome analysis.
Next to spleen, the spleen-specific genes showed relatively higher expression in kidney and fat compared to the rest of the tissues. The mean RPKM values of the spleen-specific genes were 5491, 973, and 400 in spleen, kidney and fat, respectively (Figure 13). Kidney is one of the large lymphoid organs in teleosts containing macrophages and lymphoid cells (Zapata et al., 2006; Uribe et al., 2011). The relatively high level of expression of the spleen-specific genes in adipose tissue may be attributed to presence of many populations of immune cells in fat tissues (Ferrante, 2013).

Most of the 51 spleen-specific genes have functions not related to immunity. Interestingly, upon testing a few of these genes after infection with flavobacterium, three transcripts showed differential expression associated with infection, these are contig C23964_c2_seq1_P-selectin_precursor, contig C13_c2_seq1_Hemoglobin_subunit_beta-1 and contig C83628_c0_seq1_RING_finger_protein_151 (Detailed data will be published elsewhere). These data indicate that many of the spleen-specific genes may have immune functions. Further research is still needed to test if the other spleen-specific gene functions are related to immunity. 
FCYR-MEDIATED PHAGOCYTOSIS

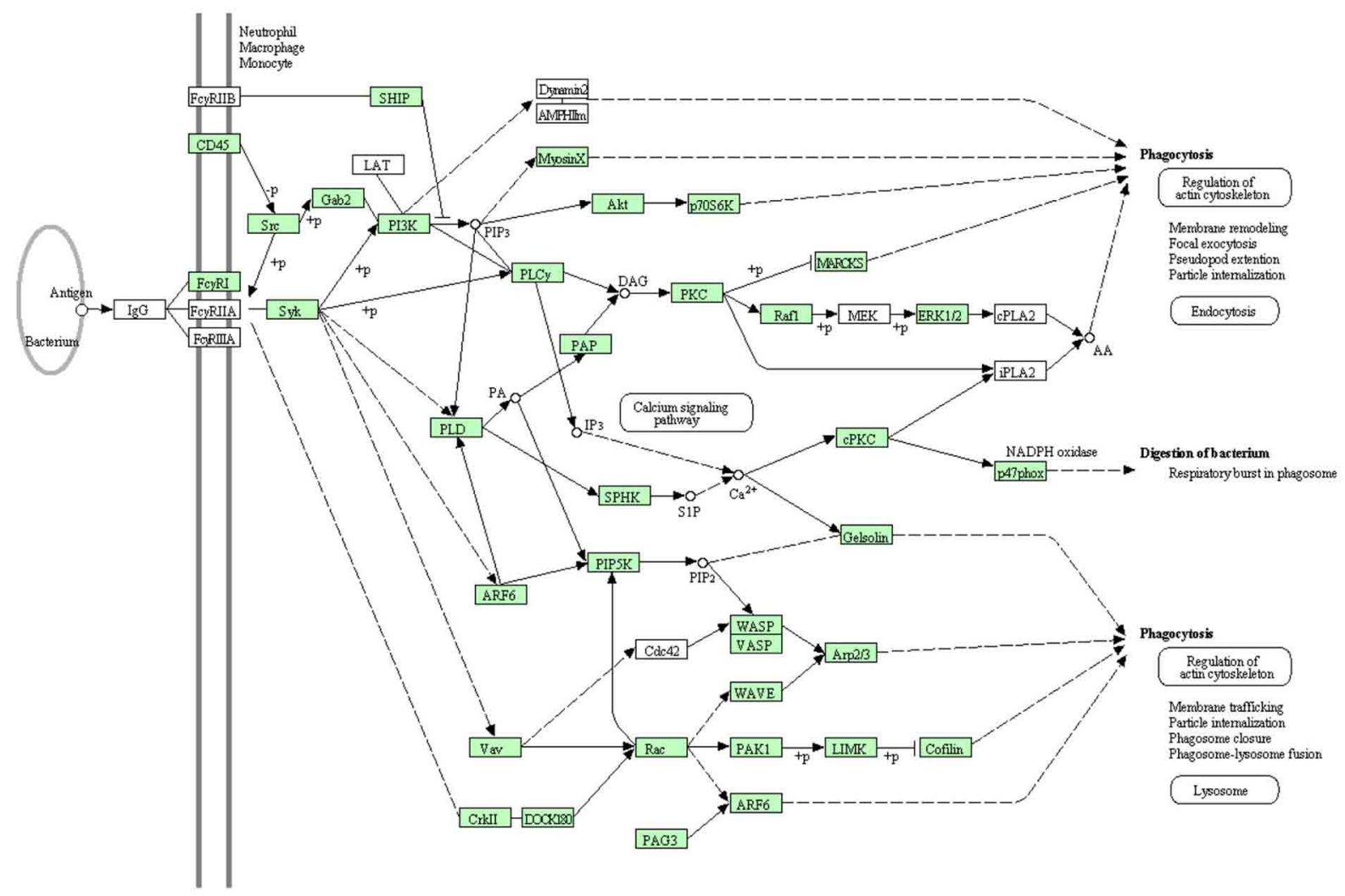

FIGURE 10 | Fc gamma R-mediated phagocytosis showing the annotated and non-annotated proteins. Proteins appearing in our transcriptome are represented in green color and absent proteins in white color.

\section{ORF/ FULL-LENGTH cDNA PREDICTION}

Full-length cDNAs are a crucial tool for many genetic and genomic studies including alternative splicing and characterization of gene duplications or pseudogenes (Xin et al., 2008). To identify full-length cDNAs in the above mentioned seven immune pathways, contigs were analyzed by the TargetIdentifier server (Min et al., 2005). A total of 38, 29, 30, 49, 31, 37, and 26 full-length cDNAs were identified in the Toll-like receptor signaling pathway, B cell receptor signaling pathway, $\mathrm{T}$ cell receptor signaling pathway, chemokine signaling pathway, Fc gamma R-mediated phagocytosis, Leukocyte transendothelial migration and NK cell mediated cytotoxicity, respectively (Tables S4-S10). Out of the total number of full-length cDNAs, there were 25, $15,18,30,24,24$, and 19 sequences with completely sequenced ORF identified in all studied immune pathways, respectively. Likewise, spleen-specific genes were analyzed by the online TargetIdentifier server (Min et al., 2005) to identify full-length cDNAs. A total of 37 full-length sequences including 24 with completely sequenced ORF were identified among the spleenspecific transcripts. Many of these transcripts were annotated for the first time in rainbow trout. Further work is needed to validate these full-length cDNAs and examine their genomic characteristics (UTR length, Kozak sequence, and conserved motifs) in detail.

\section{METHODS}

\section{TISSUE SAMPLING AND RNA ISOLATION}

Homozygous doubled haploid rainbow trout fish from the Swanson clonal line were produced at Washington State University (WSU) by androgenesis (Scheerer et al., 1986, 1991; Young et al., 1996; Robison et al., 1999). The fish, approximately $300 \mathrm{~g}$ in weight, was reared in recirculating water systems at $12-16^{\circ} \mathrm{C}$ and had sexually matured as a male prior to sampling. Spleen tissues were collected and frozen in liquid nitrogen, then shipped on ice. All samples were preserved at $-80^{\circ} \mathrm{C}$ until RNA isolation to reduce autocatalytic degradation. Total RNA was isolated from spleen tissues with TRIzol (Invitrogen, Carlsbad, CA) and purified according to the manufacturer's guidelines. Quantity of total RNA was assessed by measuring the absorbance at A260/A280 using a Nanodrop ${ }^{\mathrm{TM}}$ ND-1000 spectrophotometer (Thermo Scientific). RNA quality was checked by electrophoresis through a $1 \%(\mathrm{w} / \mathrm{v})$ agarose gel. Moreover, RNA integrity was tested using the bioanalyzer 2100 (Aglient, CA).

\section{cDNA LIBRARY PREPARATION AND ILLUMINA SEQUENCING}

RNA-Seq library preparation and sequencing were carried out by the University of Illinois at Urbana-Champaign (UIUC), 901 West Illinois street Urbana, IL 61801 USA. A RiboMinusTM 


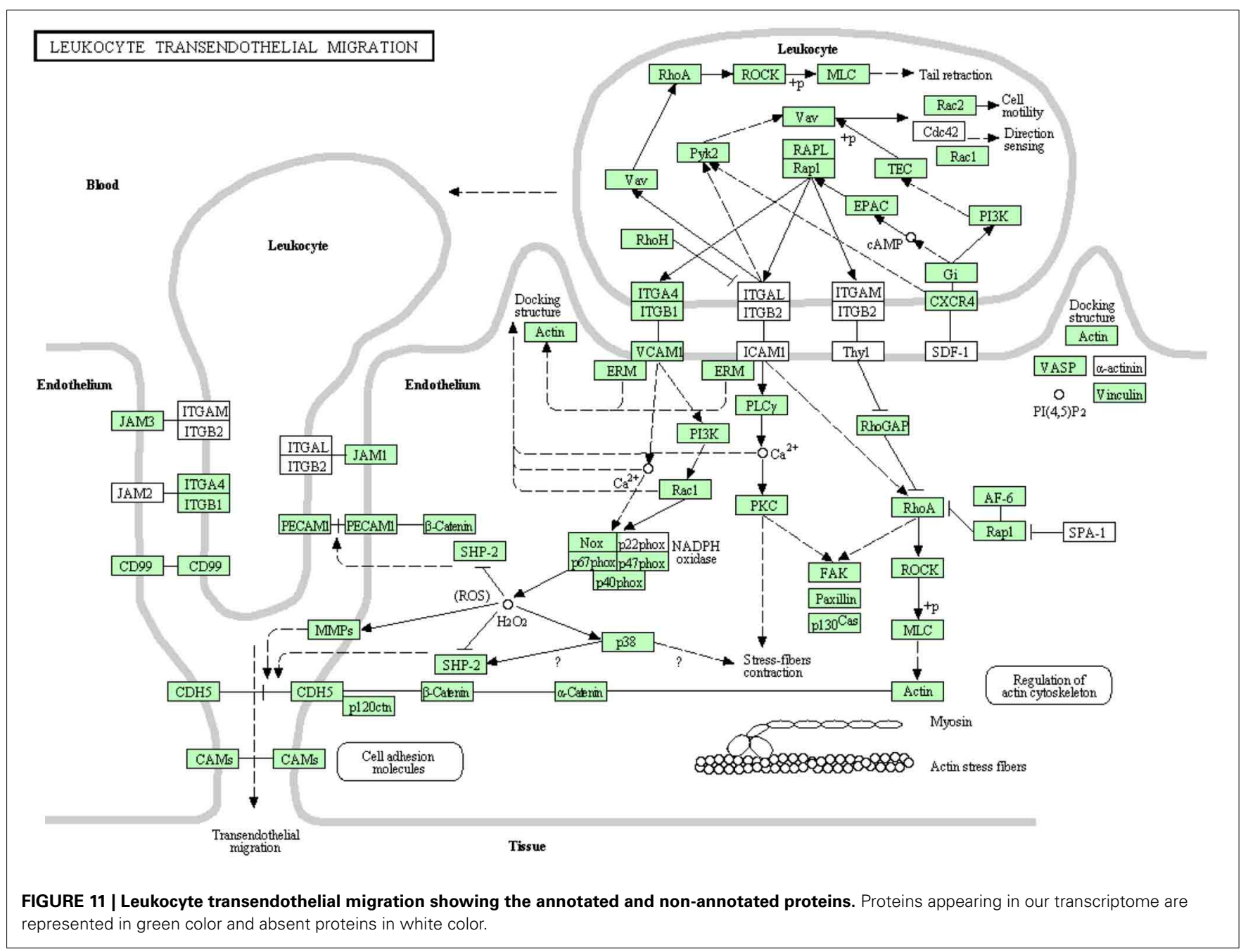

Eukaryote Kit V2 (Invitrogen, Carlsbad, CA) was used to deplete rRNA from the total RNA. cDNA libraries were constructed using $\sim 1 \mu \mathrm{g}$ of rRNA depleted RNA following the protocol of the Illumina TruSeq RNA sample preparation Kit (Illumina). The resulting double-stranded manufactured cDNA was used in the preparation of the Illumina library. The standard end-repair step was carried out first, followed by the standard ligation reaction where the end-repaired DNA along with a single A base overhang were ligated to the adaptors using T4-DNA Ligase (TrueSeq RNA Sample Prep Kit v2, Illumina, San Diego, CA). The products of the ligation reaction were purified and exposed to size selection of the target length (400-450 bp) from the gel for carrying out the ligation-mediated PCR. Cluster generation and sequencing were carried out following the cluster generation and sequencing manual from Illumina (Cluster Station User Guide and Genome Analyzer Operations Guide). All sequenced raw data were first exported in FASTQ format and are currently being uploaded to the NCBI short read archive (SRA).

\section{CLC GENOMICS DE NOVO ASSEMBLY}

De novo assembly of the expressed short reads was carried out by CLC Genomics Workbench (version 6.0; CLC bio, Aarhus,
Denmark; http://www.clcbio.com/products/clc-genomics-work bench/). The raw data were filtered by removing short, duplicated and low quality reads. CLC was run using the default settings for all parameters including a minimum contig length of $500 \mathrm{bp}$.

\section{FUNCTIONAL ANNOTATION AND GENE ONTOLOGY ANALYSIS}

Blast2Go version 2.6.5 (http://www.blast2go.com/b2ghome) was used for the functional annotation and analysis of the assembled contigs according to molecular function, biological process and cellular component ontologies. BLASTX search for sequence homology (E-value of 1.0E-3, maximum 20 hits) was carried out against NCBI's non-redundant protein database (NR). GO terms related to the established hits were extracted and modulated. The functional annotations were analyzed and statistical analysis of GO distributions was performed.

\section{IDENTIFICATION OF IMMUNE-RELATED PROTEINS}

Assembled consensus sequences were uploaded to the KEGG Automatic Annotation Server (KAAS) (Moriya et al., 2007) Ver. 1.67x (http://www.genome.jp/tools/kaas/). The functional annotation of genes was carried out by searching local BLAST against KEGG database. 


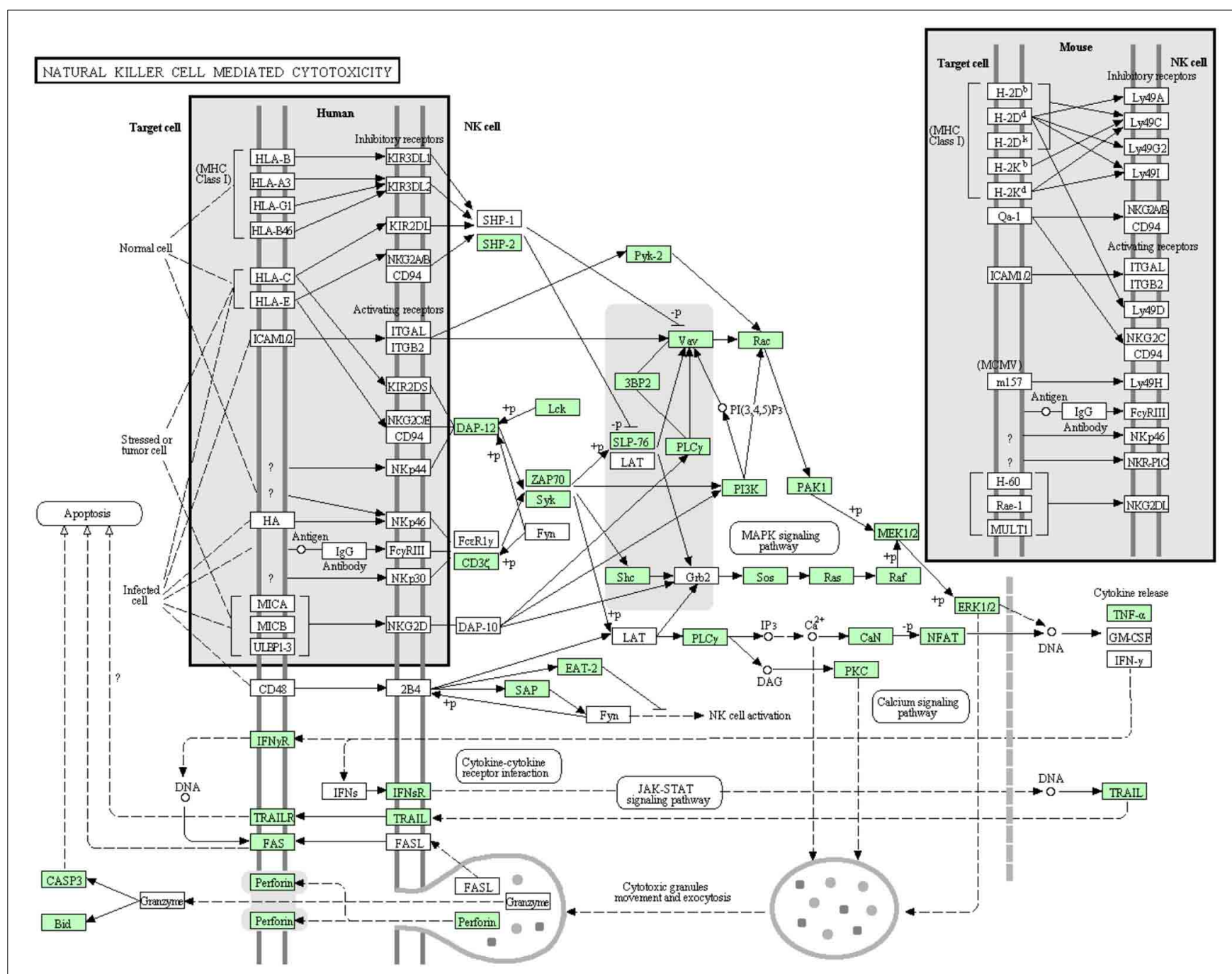

FIGURE 12 | Natural killer cell mediated cytotoxicity showing the annotated and non-annotated proteins. Proteins appearing in our transcriptome are represented in green color and absent proteins in white color.

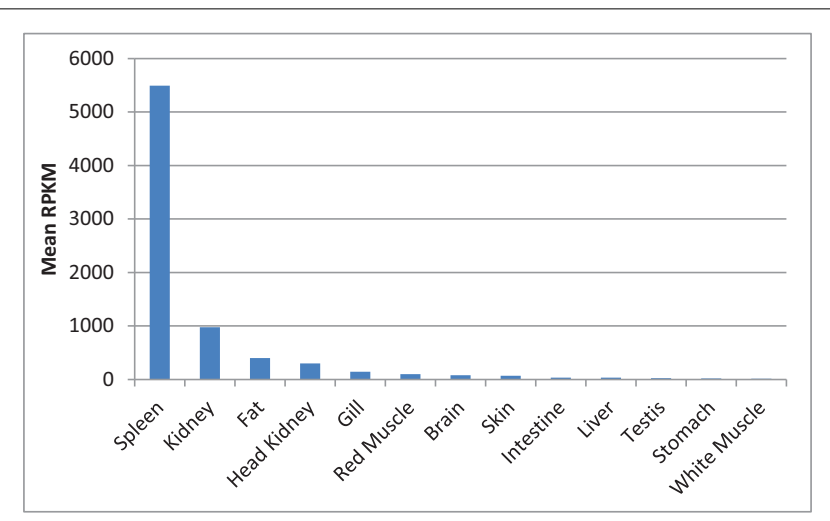

FIGURE 13 | Mean of RPKM of the spleen-specific genes in 13 tissues of rainbow trout. The mean RPKM values of the spleen-specific genes were 5491,973 , and 400 in spleen, kidney and fat, respectively.
The Bi-directional best hit (BBH) method was used to analyze and identify the immune molecules that were present and absent in the seven immune pathways containing the highest number of transcripts that showed high similarity to different members of each pathway. Transcripts were mapped to a newly assembled genome reference. The coordinate genome reference IDs of the immune-related transcripts were determined using BLASTX (cut off $E$-value of 1.00E-10) against the genome protein dataset (Berthelot et al., 2014).

\section{IDENTIFICATION OF SPLEEN-SPECIFIC GENES}

Tissue-specific genes in spleen were identified using CLC genomics workbench Baggeley's test in which expression level of a gene in spleen was compared to its expression level in 12 tissues (brain, white muscle, red muscle, fat, gill, head kidney, kidney, intestine, skin, stomach, liver and testis). For distinction of tissue-specific genes, FDR value was set as 5\% and fold change 
was at least 20 fold higher in spleen relative to the other 12 tissues. The spleen-specific genes were mapped to the newly assembled genome reference (Berthelot et al., 2014) to determine the coordinate genome reference IDs with a cutoff $E$-value of $1.00 \mathrm{E}-10$.

\section{ORF/ FULL-LENGTH cDNA PREDICTION}

All contigs annotated in the interesting KEGG immune pathways, including Toll-like receptor signaling pathway, T-cell receptor signaling pathway, B-cell receptor signaling pathway, chemokine signaling pathway, Fc gamma R-mediated phagocytosis, Leukocyte transendothelial migration and NK cell mediated cytotoxicity, in addition to spleen-specific genes were analyzed using the online TargetIdentifier server (Min et al., 2005) to look for open reading frames and putative full-length cDNAs. A BLASTX output file including the BLASTX results for all cDNA sequences in the "FASTA" file with a cutoff $E$-value of $1.00 \mathrm{E}-3$ was uploaded to the TargetIdentifier program to work properly. cDNA was considered as full-length if the sequence has a $5^{\prime}$ stop codon followed by a start codon or the sequence does not have a $5^{\prime}$ stop codon but there is an in-frame start codon present prior to the $10^{\text {th }}$ codon of the subject sequence. Based on the BLASTX results, TargetIdentifier predicts existence of an open reading frame (ORF) completely sequenced or not.

\section{ACKNOWLEDGMENTS}

This study was supported by the USDA ARS Cooperative Agreement No. 58-1930-0-059. We thank Paul Wheeler for providing tissues from the Swanson doubled haploid trout. Mention of trade names of commercial products in this publication is solely for the purpose of providing specific information and does not imply recommendation or endorsement by the U.S. Department of Agriculture.

\section{SUPPLEMENTARY MATERIAL}

The Supplementary Material for this article can be found online at: http://www.frontiersin.org/journal/10.3389/fgene. 2014.00348/abstract

\section{REFERENCES}

Allendorf, F. W., and Thorgaard, G. H. (1984). "Tetraploidy and the evolution of salmonid fishes," in Evolutionary Genetics of Fishes, ed B. J. Turner (New York, NY: Plenum Press), 1-53.

Alvarez-Pellitero, P. (2008). Fish immunity and parasite infections: from innate immunity to immunoprophylactic prospects. Vet. Immunol. Immunopathol. 126, 171-198. doi: 10.1016/j.vetimm.2008.07.013

Amish, S. J., Hohenlohe, P. A., Painter, S., Leary, R. F., Muhlfeld, C., Allendorf, F. W., et al. (2012). Rad sequencing yields a high success rate for westslope cutthroat and rainbow trout species-diagnostic snp assays. Mol. Ecol. Resour. 12, 653-660. doi: 10.1111/j.1755-0998.2012.03157.x

Ashburner, M., Ball, C. A., Blake, J. A., Botstein, D., Butler, H., Cherry, J. M., et al. (2000). Gene ontology: tool for the unification of biology. The gene ontology consortium. Nat. Genet. 25, 25-29. doi: 10.1038/75556

Backström, N., Zhang, Q., and Edwards, S. V. (2013). Evidence from a house finch (Haemorhous mexicanus) spleen transcriptome for adaptive evolution and biased gene conversion in passerine birds. Mol. Biol. Evol. 30, 1046-1050. doi: 10.1093/molbev/mst033

Baoprasertkul, P., Peatman, E., Abernathy, J., and Liu, Z. (2007a). Structural characterisation and expression analysis of toll-like receptor 2 gene from catfish. Fish Shellfish Immunol. 22, 418-426. doi: 10.1016/j.fsi.2006.04.005
Baoprasertkul, P., Xu, P., Peatman, E., Kucuktas, H., and Liu, Z. (2007b). Divergent toll-like receptors in catfish (ictalurus punctatus): tlr5s, tlr20, tlr21. Fish Shellfish Immunol. 23, 1218-1230. doi: 10.1016/j.fsi.2007.06.002

Barton, G. M., and Medzhitov, R. (2003). Toll-like receptor signaling pathways. Science 300, 1524-1525. doi: 10.1126/science.1085536

Batista, F. D., and Neuberger, M. S. (1998). Affinity dependence of the b cell response to antigen: a threshold, a ceiling, and the importance of off-rate. Immunity 8, 751-759. doi: 10.1016/S1074-7613(00) 80580-4

Berthelot, C., Brunet, F., Chalopin, D., Juanchich, A., Bernard, M., Noël, B., et al. (2014). The rainbow trout genome provides novel insights into evolution after whole-genome duplication in vertebrates. Nat. Commun. 5:3657. doi: $10.1038 /$ ncomms4657

Bilodeau, A. L., and Waldbieser, G. C. (2005). Activation of tlr3 and tlr5 in channel catfish exposed to virulent edwardsiella ictaluri. Dev. Comp. Immunol. 29, 713-721. doi: 10.1016/j.dci.2004.12.002

Bobe, J., Montfort, J., Nguyen, T., and Fostier, A. (2006). Identification of new participants in the rainbow trout (Oncorhynchus mykiss) oocyte maturation and ovulation processes using cdna microarrays. Reprod. Biol. Endocrinol. 4:39. doi: 10.1186/1477-7827-4-39

Boussaha, M., Guyomard, R., Cabau, C., Esquerré, D., and Quillet, E. (2012). Development and characterisation of an expressed sequence tags (est)-derived single nucleotide polymorphisms (snps) resource in rainbow trout. BMC Genomics 13:238. doi: 10.1186/1471-2164-13-238

Cerdà, J., Mercadé, J., Lozano, J. J., Manchado, M., Tingaud-Sequeira, A., Astola, A., et al. (2008). Genomic resources for a commercial flatfish, the senegalese sole (solea senegalensis): est sequencing, oligo microarray design, and development of the soleamold bioinformatic platform. BMC Genomics 9:508. doi: 10.1186/1471-2164-9-508

Chaves-Pozo, E., Mulero, V., Meseguer, J., and García Ayala, A. (2005). Professional phagocytic granulocytes of the bony fish gilthead seabream display functional adaptation to testicular microenvironment. J. Leukoc. Biol. 78, 345-351. doi: 10.1189/jlb.0205120

Chiu, S. C., Tsao, S. W., Hwang, P. I., Vanisree, S., Chen, Y. A., and Yang, N. S. (2010). Differential functional genomic effects of anti-inflammatory phytocompounds on immune signaling. BMC Genomics 11:513. doi: 10.1186/1471-216411-513

Christensen, K. A., Brunelli, J. P., Lambert, M. J., Dekoning, J., Phillips, R. B., and Thorgaard, G. H. (2013). Identification of single nucleotide polymorphisms from the transcriptome of an organism with a whole genome duplication. BMC Bioinformatics 14:325. doi: 10.1186/1471-2105-14-325

Colussi, S., Prearo, M., Bertuzzi, S. A., Scanzio, T., Peletto, S., Favaro, L., et al. (2014). Association of a specific major histocompatibility complex class II $\beta$ single nucleotide polymorphism with resistance to lactococcosis in rainbow trout, Oncorhynchus mykiss (walbaum). J. Fish Dis. doi: 10.1111/jfd.12193. [Epub ahead of print].

Conesa, A., Götz, S., García-Gómez, J. M., Terol, J., Talón, M., and Robles, M. (2005). Blast2go: a universal tool for annotation, visualization and analysis in functional genomics research. Bioinformatics 21, 3674-3676. doi: 10.1093/bioinformatics/bti610

Consortium, G. O. (2008). The gene ontology project in 2008. Nucleic Acids Res. 36, D440-D444. doi: 10.1093/nar/gkm883

Daniels, G. D., Zou, J., Charlemagne, J., Partula, S., Cunningham, C., and Secombes, C. J. (1999). Cloning of two chemokine receptor homologs (cxcr4 and cc-r7) in rainbow trout Oncorhynchus mykiss. J. Leukoc. Biol. 65, 684-690.

Dixon, B., Luque, A., Abós, B., Castro, R., González-Torres, L., and Tafalla, C. (2013). Molecular characterization of three novel chemokine receptors in rainbow trout (Oncorhynchus mykiss). Fish Shellfish Immunol. 34, 641-651. doi: 10.1016/j.fsi.2012.12.003

Djari, A., Esquerré, D., Weiss, B., Martins, F., Meersseman, C., Boussaha, M., et al. (2013). Gene-based single nucleotide polymorphism discovery in bovine muscle using next-generation transcriptomic sequencing. BMC Genomics 14:307. doi: 10.1186/1471-2164-14-307

Espenes, A., Press, C., Danneving, B., and Landsverk, T. (1995). Immune-complex trapping in the splenic ellipsoids of rainbow trout (Oncorhynchus mykiss). Cell Tissue Res. 282, 41-48.

Ferrante, A. W. (2013). The immune cells in adipose tissue. Diabetes Obes. Metab. 15(Suppl. 3), 34-38. doi: 10.1111/dom.12154 
Fox, S. E., Christie, M. R., Marine, M., Priest, H. D., Mockler, T. C., and Blouin, M. S. (2014). Sequencing and characterization of the anadromous steelhead (Oncorhynchus mykiss) transcriptome. Mar. Genomics. 15, 13-15. doi: 10.1016/j.margen.2013.12.001

Götz, S., García-Gómez, J. M., Terol, J., Williams, T. D., Nagaraj, S. H., Nueda, M. J., et al. (2008). High-throughput functional annotation and data mining with the blast2go suite. Nucleic Acids Res. 36, 3420-3435. doi: 10.1093/nar/ gkn176

Grabherr, M. G., Haas, B. J., Yassour, M., Levin, J. Z., Thompson, D. A., Amit, I., et al. (2011). Full-length transcriptome assembly from rna-seq data without a reference genome. Nat. Biotechnol. 29, 644-652. doi: 10.1038/nbt.1883

Guyomard, R., Boussaha, M., Krieg, F., Hervet, C., and Quillet, E. (2012). A synthetic rainbow trout linkage map provides new insights into the salmonid whole genome duplication and the conservation of synteny among teleosts. BMC Genet. 13:15. doi: 10.1186/1471-2156-13-15

Hogan, R. J., Stuge, T. B., Clem, L. W., Miller, N. W., and Chinchar, V. G. (1996). Anti-viral cytotoxic cells in the channel catfish (ictalurus punctatus). Dev. Comp. Immunol. 20, 115-127. doi: 10.1016/0145-305X(95)00043-S

Horiguchi, K., Yagi, S., Ono, K., Nishiura, Y., Tanaka, M., Ishida, M., et al. (2004). Prolactin gene expression in mouse spleen helper t cells. J. Endocrinol. 183, 639-646. doi: 10.1677/joe.1.05744

Houston, D. D., Elzinga, D. B., Maughan, P. J., Smith, S. M., Kauwe, J. S., Evans, R. P., et al. (2012). Single nucleotide polymorphism discovery in cutthroat trout subspecies using genome reduction, barcoding, and 454 pyro-sequencing. BMC Genomics 13:724. doi: 10.1186/1471-2164-13-724

Huang, Y., Huang, X., Yan, Y., Cai, J., Ouyang, Z., Cui, H., et al. (2011). Transcriptome analysis of orange-spotted grouper (epinephelus coioides) spleen in response to singapore grouper iridovirus. BMC Genomics 12:556. doi: 10.1186/1471-2164-12-556

Janeway, C. A., and Medzhitov, R. (2002). Innate immune recognition. Annu. Rev. Immunol. 20, 197-216. doi: 10.1146/annurev.immunol.20.083001.084359

Jault, C., Pichon, L., and Chluba, J. (2004). Toll-like receptor gene family and tir-domain adapters in Danio rerio. Mol. Immunol. 40, 759-771. doi: 10.1016/j.molimm.2003.10.001

Kaiser, P., Howell, J., Fife, M., Sadeyen, J. R., Salmon, N., Rothwell, L., et al. (2008). Integrated immunogenomics in the chicken: deciphering the immune response to identify disease resistance genes. Dev. Biol. (Basel) 132, 57-66. doi: $10.1159 / 000317144$

Kanehisa, M., and Goto, S. (2000). Kegg: Kyoto encyclopedia of genes and genomes. Nucleic Acids Res. 28, 27-30. doi: 10.1093/nar/28.1.27

Kanehisa, M., Goto, S., Sato, Y., Furumichi, M., and Tanabe, M. (2012). Kegg for integration and interpretation of large-scale molecular data sets. Nucleic Acids Res. 40, D109-D114. doi: 10.1093/nar/gkr988

Khan, W. I., and Ghia, J. E. (2010). Gut hormones: emerging role in immune activation and inflammation. Clin. Exp. Immunol. 161, 19-27. doi: 10.1111/j.13652249.2010.04150.x

Köllner, B., Wasserrab, B., Kotterba, G., and Fischer, U. (2002). Evaluation of immune functions of rainbow trout (Oncorhynchus mykiss)-how can environmental influences be detected? Toxicol. Lett. 131, 83-95. doi: 10.1016/S03784274(02)00044-9

Kongchum, P., Palti, Y., Hallerman, E. M., Hulata, G., and David, L. (2010). Snp discovery and development of genetic markers for mapping innate immune response genes in common carp (cyprinus carpio). Fish Shellfish Immunol. 29, 356-361. doi: 10.1016/j.fsi.2010.04.013

Kruglov, A. A., Grivennikov, S. I., Kuprash, D. V., Winsauer, C., Prepens, S., Seleznik, G. M., et al. (2013). Nonredundant function of soluble lt $\alpha 3$ produced by innate lymphoid cells in intestinal homeostasis. Science 342, 1243-1246. doi: 10.1126/science. 1243364

Kurosaki, T., Shinohara, H., and Baba, Y. (2010). B cell signaling and fate decision. Annu. Rev. Immunol. 28, 21-55. doi: 10.1146/annurev.immunol.021908.132541

Lanier, L. L. (2003). Natural killer cell receptor signaling. Curr. Opin. Immunol. 15, 308-314. doi: 10.1016/S0952-7915(03)00039-6

Lee, A. P., Kerk, S. Y., Tan, Y. Y., Brenner, S., and Venkatesh, B. (2011). Ancient vertebrate conserved noncoding elements have been evolving rapidly in teleost fishes. Mol. Biol. Evol. 28, 1205-1215. doi: 10.1093/molbev/msq304

Leeds, T. D., Silverstein, J. T., Weber, G. M., Vallejo, R. L., Palti, Y., Rexroad, C. E. 3rd., et al. (2010). Response to selection for bacterial cold water disease resistance in rainbow trout. J. Anim. Sci. 88, 1936-1946. doi: 10.2527/jas. 2009-2538
Liu, X., Yu, X., Zack, D. J., Zhu, H., and Qian, J. (2008). Tiger: a database for tissue-specific gene expression and regulation. BMC Bioinformatics 9:271. doi: 10.1186/1471-2105-9-271

Mahabady, M., Morovvati, H., Arefi, A., and Karamifar, M. (2012). Anatomical and histomorphological study of spleen and pancreas in berzem (barbus pectoralis). World J. Fish Mar. Sci. 4, 263-267. doi: 10.5829/idosi.wjfms.2012.04.03. 61283

Medzhitov, R., and Janeway, J. (2000). Innate immune recognition: mechanisms and pathways. Immunol. Rev. 173, 89-97. doi: 10.1034/j.1600065X.2000.917309.x

Meijer, A. H., Gabby Krens, S. F., Medina Rodriguez, I. A., He, S., Bitter, W., Ewa Snaar-Jagalska, B., et al. (2004). Expression analysis of the toll-like receptor and tir domain adaptor families of zebrafish. Mol. Immunol. 40, 773-783. doi: 10.1016/j.molimm.2003.10.003

Min, X. J., Butler, G., Storms, R., and Tsang, A. (2005). Targetidentifier: a webserver for identifying full-length cdnas from est sequences. Nucleic Acids Res. 33, W669-W672. doi: 10.1093/nar/gki436

Moody, C., Serreze, D., and Reno, P. (1985). Non-specific cytotoxicity activity of teleost leukocytes. Dev. Comp. Immunol. 9, 51-64. doi: 10.1016/0145305X(85)90059-X

Moriya, Y., Itoh, M., Okuda, S., Yoshizawa, A. C., and Kanehisa, M. (2007). Kaas: an automatic genome annotation and pathway reconstruction server. Nucleic Acids Res. 35, W182-W185. doi: 10.1093/nar/gkm321

Muller, W. A. (2011). Mechanisms of leukocyte transendothelial migration. Annu. Rev. Pathol. 6, 323-344. doi: 10.1146/annurev-pathol-011110-130224

Muller, W. A. (2013). Getting leukocytes to the site of inflammation. Vet. Pathol. 50, 7-22. doi: 10.1177/0300985812469883

Nie, Q., Sandford, E. E., Zhang, X., Nolan, L. K., and Lamont, S. J. (2012). Deep sequencing-based transcriptome analysis of chicken spleen in response to avian pathogenic escherichia coli (apec) infection. PLoS ONE 7:e41645. doi: 10.1371/journal.pone.0041645

Nya, E. J., and Austin, B. (2011). Development of immunity in rainbow trout (Oncorhynchus mykiss, walbaum) to aeromonas hydrophila after the dietary application of garlic. Fish Shellfish Immunol. 30, 845-850. doi: 10.1016/j.fsi.2011.01.008

Ortega-Villaizan, M., Chico, V., Falco, A., Perez, L., Coll, J. M., and Estepa, A. (2009). The rainbow trout tlr9 gene and its role in the immune responses elicited by a plasmid encoding the glycoprotein $g$ of the viral haemorrhagic septicaemia rhabdovirus (vhsv). Mol. Immunol. 46, 1710-1717. doi: 10.1016/j.molimm.2009.02.006

Oshiumi, H., Tsujita, T., Shida, K., Matsumoto, M., Ikeo, K., and Seya, T. (2003). Prediction of the prototype of the human toll-like receptor gene family from the pufferfish, fugu rubripes, genome. Immunogenetics 54, 791-800. doi: 10.1007/s00251-002-0519-8

Pacheco, P., White, D., and Sulchek, T. (2013). Effects of microparticle size and fc density on macrophage phagocytosis. PLoS ONE 8:e60989. doi: 10.1371/journal.pone.0060989

Palti, Y., Gahr, S. A., Hansen, J. D., and Rexroad, C. E. 3rd. (2004). Characterization of a new bac library for rainbow trout: evidence for multi-locus duplication. Anim. Genet. 35, 130-133. doi: 10.1111/j.1365-2052.2004.01112.x

Palti, Y., Gahr, S. A., Purcell, M. K., Hadidi, S., Rexroad, C. E., and Wiens, G. D. (2010a). Identification, characterization and genetic mapping of tlr7, tlr8al and tlr8a2 genes in rainbow trout (Oncorhynchus mykiss). Dev. Comp. Immunol. 34, 219-233. doi: 10.1016/j.dci.2009.10.002

Palti, Y., Gao, G., Miller, M. R., Vallejo, R. L., Wheeler, P. A., Quillet, E., et al. (2014). A resource of single-nucleotide polymorphisms for rainbow trout generated by restriction-site associated DNA sequencing of doubled haploids. Mol. Ecol. Resour. 14, 588-596. doi: 10.1111/1755-0998. 12204

Palti, Y., Genet, C., Luo, M. C., Charlet, A., Gao, G., Hu, Y., et al. (2011). A first generation integrated map of the rainbow trout genome. BMC Genomics 12, 180-180. doi: 10.1186/1471-2164-12-180

Palti, Y., Rodriguez, M. F., Gahr, S. A., Purcell, M. K., Rexroad, C. E., and Wiens, G. D. (2010b). Identification, characterization and genetic mapping of tlr1 loci in rainbow trout (Oncorhynchus mykiss). Fish Shellfish Immunol. 28, 918-926. doi: 10.1016/j.fsi.2010.02.002

Pease, J. E., and Williams, T. J. (2006). The attraction of chemokines as a target for specific anti-inflammatory therapy. Br. J. Pharmacol. 147(Suppl. 1), S212-S221. doi: 10.1038/sj.bjp.0706475 
Pereiro, P., Balseiro, P., Romero, A., Dios, S., Forn-Cuni, G., Fuste, B., et al. (2012). High-throughput sequence analysis of turbot (scophthalmus maximus) transcriptome using 454-pyrosequencing for the discovery of antiviral immune genes. PLoS ONE 7:e35369. doi: 10.1371/journal.pone.0035369

Raida, M. K., and Buchmann, K. (2009). Innate immune response in rainbow trout (Oncorhynchus mykiss) against primary and secondary infections with yersinia ruckeri o1. Dev. Comp. Immunol. 33, 35-45. doi: 10.1016/j.dci.2008.07.001

Ravi, V., and Venkatesh, B. (2008). Rapidly evolving fish genomes and teleost diversity. Curr. Opin. Genet. Dev. 18, 544-550. doi: 10.1016/j.gde.2008.11.001

Rebl, A., Siegl, E., Köllner, B., Fischer, U., and Seyfert, H. M. (2007). Characterization of twin toll-like receptors from rainbow trout (Oncorhynchus mykiss): evolutionary relationship and induced expression by aeromonas salmonicida salmonicida. Dev. Comp. Immunol. 31, 499-510. doi: 10.1016/j.dci.2006.08.007

Rexroad, C. E., Lee, Y., Keele, J. W., Karamycheva, S., Brown, G., Koop, B., et al. (2003). Sequence analysis of a rainbow trout cdna library and creation of a gene index. Cytogenet. Genome Res. 102, 347-354. doi: 10.1159/000075773

Rexroad, C. E., Palti, Y., Gahr, S. A., and Vallejo, R. L. (2008). A second generation genetic map for rainbow trout (Oncorhynchus mykiss). BMC Genet. 9:74. doi: 10.1186/1471-2156-9-74

Robison, B., Wheeler, P., and Thorgaard, G. (1999). Variation in development rate among clonal lines of rainbow trout (Oncorhynchus mykiss). Aquaculture 173, 131-141. doi: 10.1016/S0044-8486(98)00481-5

Rodriguez, M. F., Wiens, G. D., Purcell, M. K., and Palti, Y. (2005). Characterization of toll-like receptor 3 gene in rainbow trout (Oncorhynchus mykiss). Immunogenetics 57, 510-519. doi: 10.1007/s00251-005-0013-1

Sabban, E., Marchesi, V., Adesnik, M., and Sabatini, D. D. (1981). Erythrocyte membrane protein band 3: its biosynthesis and incorporation into membranes. J. Cell Biol. 91, 637-646. doi: 10.1083/jcb.91.3.637

Sakamoto, T., Danzmann, R. G., Gharbi, K., Howard, P., Ozaki, A., Khoo, S. K., et al. (2000). A microsatellite linkage map of rainbow trout (Oncorhynchus mykiss) characterized by large sex-specific differences in recombination rates. Genetics 155, 1331-1345.

Salem, M., Kenney, P. B., Rexroad, C. E., and Yao, J. (2008). Development of a $37 \mathrm{k}$ high-density oligonucleotide microarray: a new tool for functional genome research in rainbow trout. J. Fish Biol. 72, 2187-2206. doi: 10.1111/j.10958649.2008.01860.x

Salem, M., Rexroad, C. E., Wang, J., Thorgaard, G. H., and Yao, J. (2010). Characterization of the rainbow trout transcriptome using sanger and 454pyrosequencing approaches. BMC Genomics 11:564. doi: 10.1186/1471-216411-564

Salem, M., Vallejo, R. L., Leeds, T. D., Palti, Y., Liu, S., Sabbagh, A., et al. (2012). Rna-seq identifies snp markers for growth traits in rainbow trout. PLoS ONE 7:e36264. doi: 10.1371/journal.pone.0036264

Sánchez, C. C., Smith, T. P., Wiedmann, R. T., Vallejo, R. L., Salem, M., Yao, J., et al. (2009). Single nucleotide polymorphism discovery in rainbow trout by deep sequencing of a reduced representation library. BMC Genomics 10:559. doi: 10.1186/1471-2164-10-559

Sanchez, C. C., Weber, G. M., Gao, G., Cleveland, B. M., Yao, J., and Rexroad, C. E. 3rd. (2011). Generation of a reference transcriptome for evaluating rainbow trout responses to various stressors. BMC Genomics 12:626. doi: 10.1186/14712164-12-626

Scheerer, P., Allendorf, F., and Knudsen, K. (1986). Androgenetic rainbow trout produced from inbred and outbred sperm show similar survival. Aquaculture 57, 289-298. doi: 10.1016/0044-8486(86)90207-3

Scheerer, P., Thorgaard, G., and Allendorf, F. (1991). Genetic analysis of androgenetic rainbow trout. J. Exp. Zool. 260, 382-390. doi: 10.1002/jez.14026 00312

Skamene, E., and Pietrangeli, C. E. (1991). Genetics of the immune response to infectious pathogens. Curr. Opin. Immunol. 3, 511-517. doi: 10.1016/09527915(91)90013-Q

Takano, T., Kondo, H., Hirono, I., Endo, M., Saito-Taki, T., and Aoki, T. (2011). Toll-Like Receptors in Teleosts. Selangor: Fish Health Section, Asian Fisheries Society.

Takeda, K., and Akira, S. (2004). Tlr signaling pathways. Semin. Immunol. 16, 3-9. doi: 10.1016/j.smim.2003.10.003

Tarantino, G., Savastano, S., Capone, D., and Colao, A. (2011). Spleen: a new role for an old player? World J. Gastroenterol. 17, 3776-3784. doi: 10.3748/wjg.v17.i33.3776
Tavares-Dias, M., and Oliveira, S. R. (2009). A review of the blood coagulation system of fish. Braz. J. Biosci. 7, 205-224.

Taylor, E. B., Tamkee, P., Keeley, E. R., and Parkinson, E. A. (2011). Conservation prioritization in widespread species: the use of genetic and morphological data to assess population distinctiveness in rainbow trout (Oncorhynchus mykiss) from british columbia, canada. Evol. Appl. 4, 100-115. doi: 10.1111/j.17524571.2010.00136.x

Thorgaard, G. H., Bailey, G. S., Williams, D., Buhler, D. R., Kaattari, S. L., Ristow, S. S., et al. (2002). Status and opportunities for genomics research with rainbow trout. Comp. Biochem. Physiol. B Biochem. Mol. Biol. 133, 609-646. doi: 10.1016/S1096-4959(02)00167-7

Tilton, S. C., Gerwick, L. G., Hendricks, J. D., Rosato, C. S., Corley-Smith, G., Givan, S. A., et al. (2005). Use of a rainbow trout oligonucleotide microarray to determine transcriptional patterns in aflatoxin b1-induced hepatocellular carcinoma compared to adjacent liver. Toxicol. Sci. 88, 319-330. doi: $10.1093 /$ toxsci/kfi309

Tsujita, T., Tsukada, H., Nakao, M., Oshiumi, H., Matsumoto, M., and Seya, T. (2004). Sensing bacterial flagellin by membrane and soluble orthologs of tolllike receptor 5 in rainbow trout (onchorhynchus mikiss). J. Biol. Chem. 279, 48588-48597. doi: 10.1074/jbc.M407634200

Ullal, A. J., Litaker, R. W., and Noga, E. J. (2008). Antimicrobial peptides derived from hemoglobin are expressed in epithelium of channel catfish (ictalurus punctatus, rafinesque). Dev. Comp. Immunol. 32, 1301-1312. doi: 10.1016/j.dci.2008.04.005

Ungar, G. (1945). Endocrine function of the spleen and its participation in the pituitary-adrenal response to stress. Endocrinology 37, 329-340. doi: 10.1210/endo-37-5-329

Uribe, C., Folch, H., Enriquez, R., and Moran, G. (2011). Innate and adaptive immunity in teleost fish: a review. Vet. Med. 56, 486-503.

Van Muiswinkel, W. B., Wiegertjes, G. F., and Stet, R. J. M. (1999). The influence of environmental and genetic factors on the disease resistance of fish. Aquaculture 172, 103-110. doi: 10.1016/S0044-8486(98)00444-X

Wang, X., Xu, R., Wang, R., and Liu, A. (2012). Transcriptome analysis of sacha inchi (plukenetia volubilis 1.) seeds at two developmental stages. BMC Genomics 13:716. doi: 10.1186/1471-2164-13-716

Whyte, S. K. (2007). The innate immune response of finfish-a review of current knowledge. Fish Shellfish Immunol. 23, 1127-1151. doi: 10.1016/j.fsi.2007.06.005

Wiegertjes, G. F., Stet, R. J., Parmentier, H. K., and Van Muiswinkel, W. B. (1996). Immunogenetics of disease resistance in fish: a comparative approach. Dev. Comp. Immunol. 20, 365-381. doi: 10.1016/S0145-305X(96) 00032-8

Wiens, G. D., Lapatra, S. E., Welch, T. J., Evenhuis, J. P., Rexroad, C. E., and Leeds, T. D. (2013a). On-farm performance of rainbow trout (Oncorhynchus mykiss) selectively bred for resistance to bacterial cold water disease: effect of rearing environment on survival phenotype. Aquaculture 388-391, 128-136. doi: 10.1016/j.aquaculture.2013.01.018

Wiens, G. D., Vallejo, R. L., Leeds, T. D., Palti, Y., Hadidi, S., Liu, S., et al. (2013b). Assessment of genetic correlation between bacterial cold water disease resistance and spleen index in a domesticated population of rainbow trout: identification of qtl on chromosome omy19. PLoS ONE 8:e75749. doi: 10.1371/journal.pone.0075749

Wong, S., Waldrop, T., Summerfelt, S., Davidson, J., Barrows, F., Kenney, P. B., et al. (2013). Aquacultured rainbow trout (Oncorhynchus mykiss) possess a large core intestinal microbiota that is resistant to variation in diet and rearing density. Appl. Environ. Microbiol. 79, 4974-4984. doi: 10.1128/AEM. 00924-13

Wu, X. N. (1998). Current concept of spleen-stomach theory and spleen deficiency syndrome in tcm. World J. Gastroenterol. 4, 2-6.

Xiang, L. X., He, D., Dong, W. R., Zhang, Y. W., and Shao, J. Z. (2010). Deep sequencing-based transcriptome profiling analysis of bacteria-challenged lateolabrax japonicus reveals insight into the immune-relevant genes in marine fish. BMC Genomics 11:472. doi: 10.1186/1471-2164-11-472

Xiao, S. J., Zhang, C., Zou, Q., and Ji, Z. L. (2010). Tisged: a database for tissue-specific genes. Bioinformatics 26, 1273-1275. doi: 10.1093/bioinformatics/btq109

Xin, D., Hu, L., and Kong, X. (2008). Alternative promoters influence alternative splicing at the genomic level. PLOS ONE 3:e2377. doi: 10.1371/journal.pone.0002377 
Yang, D., Liu, Q., Yang, M., Wu, H., Wang, Q., Xiao, J., et al. (2012). Rna-seq liver transcriptome analysis reveals an activated mhc-i pathway and an inhibited mhc-ii pathway at the early stage of vaccine immunization in zebrafish. BMC Genomics 13:319. doi: 10.1186/1471-2164-13-319

Yoshinaga, K., Okamoto, N., Kurata, O., and Ikeda, Y. (1994). Individual variations of natural killer activity of rainbow trout leukocytes against ipn virus-infected and uninfected rtg-2 cells. Fish Pathol. 29, 1-4. doi: 10.3147/jsfp.29.1

Young, W. P., Wheeler, P. A., Coryell, V. H., Keim, P., and Thorgaard, G. H. (1998). A detailed linkage map of rainbow trout produced using doubled haploids. Genetics 148, 839-850.

Young, W. P., Wheeler, P. A., Fields, R. D., and Thorgaard, G. H. (1996). DNA fingerprinting confirms isogenicity of androgenetically derived rainbow trout lines. J. Hered. 87, 77-80. doi: 10.1093/oxfordjournals.jhered.a022960

Zapata, A., Chibá, A., and Varas, A. (1997). "Cells and tissues of the immune system of fish," in The Fish Immune System: Organism, Pathogen, and Environment, eds G. Iwama and T. Nakanishi (San Diego, CA: Academic Press), 1-62.

Zapata, A., Diez, B., Cejalvo, T., Gutiérrez-De Frías, C., and Cortés, A. (2006). Ontogeny of the immune system of fish. Fish Shellfish Immunol. 20, 126-136. doi: 10.1016/j.fsi.2004.09.005

Zenz, R., Eferl, R., Scheinecker, C., Redlich, K., Smolen, J., Schonthaler, H. B., et al. (2008). Activator protein 1 (fos/jun) functions in inflammatory bone and skin disease. Arthritis Res. Ther. 10:201. doi: 10.1186/ar2338
Zhang, J., Yang, Y., Wang, Y., Wang, Z., Yin, M., and Shen, X. (2011). Identification of hub genes related to the recovery phase of irradiation injury by microarray and integrated gene network analysis. PLOS ONE 6:e24680. doi: 10.1371/journal.pone. 0024680

Conflict of Interest Statement: The authors declare that the research was conducted in the absence of any commercial or financial relationships that could be construed as a potential conflict of interest.

Received: 08 July 2014; accepted: 16 September 2014; published online: 14 October 2014.

Citation: Ali A, Rexroad CE, Thorgaard GH, Yao J and Salem M (2014) Characterization of the rainbow trout spleen transcriptome and identification of immune-related genes. Front. Genet. 5:348. doi: 10.3389/fgene.2014.00348

This article was submitted to Livestock Genomics, a section of the journal Frontiers in Genetics.

Copyright (c) 2014 Ali, Rexroad, Thorgaard, Yao and Salem. This is an open-access article distributed under the terms of the Creative Commons Attribution License (CC BY). The use, distribution or reproduction in other forums is permitted, provided the original author(s) or licensor are credited and that the original publication in this journal is cited, in accordance with accepted academic practice. No use, distribution or reproduction is permitted which does not comply with these terms. 